\title{
The efficient global primitive equation climate model SPEEDO V2.0
}

\author{
C. A. Severijns and W. Hazeleger \\ Royal Netherlands Meteorological Institute (KNMI), de Bilt, The Netherlands
}

Received: 10 August 2009 - Published in Geosci. Model Dev. Discuss.: 26 August 2009

Revised: 14 January 2010 - Accepted: 19 January 2010 - Published: 10 February 2010

\begin{abstract}
The efficient primitive-equation coupled atmosphere-ocean model SPEEDO V2.0 is presented. The model includes an interactive sea-ice and land component. SPEEDO is a global earth system model of intermediate complexity. It has a horizontal resolution of T30 (triangular truncation at wave number 30 ) and 8 vertical layers in the atmosphere, and a horizontal resolution of 2 degrees and 20 levels in the ocean. The parameterisations in SPEEDO are developed in such a way that it is a fast model suitable for large ensembles or long runs (of $O\left(10^{4}\right)$ years) on a typical current workstation. The model has no flux correction. We compare the mean state and inter-annual variability of the model with observational fields of the atmosphere and ocean. In particular the atmospheric circulation, the midlatitude patterns of variability and teleconnections from the tropics are well simulated. To show the capabilities of the model, we performed a long control run and an ensemble experiment with enhanced greenhouse gases. The long control run shows that the model is stable. $\mathrm{CO}_{2}$ doubling and future climate change scenario experiments show a climate sensitivity of $1.84 \mathrm{KW}^{-1} \mathrm{~m}^{2}$, which is within the range of state-of-the-art climate models. The spatial response patterns are comparable to state-of-the-art, higher resolution models. However, for very high greenhouse gas concentrations the parameterisations are not valid. We conclude that the model is suitable for past, current and future climate simulations and for exploring wide parameter ranges and mechanisms of variability. However, as with any model, users should be careful when using the model beyond the range of physical realism of the parameterisations and model setup.
\end{abstract}

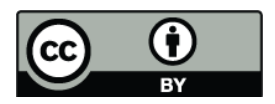

Correspondence to: C. A. Severijns (c.severijns@knmi.nl)

\section{Introduction}

Numerical models of the earth system can be used for understanding processes in the earth system, understanding past climate changes and predicting future changes. Global stateof-the-art earth system models are computationally expensive which limits their use to simulate long time scales, to make large ensembles or to cover wide parameter ranges. For these scientific purposes computationally efficient earth system models of intermediate complexity (EMICs) (Claussen et al., 2002) have been developed. To achieve this computational efficiency, many EMICs have limited spatial resolution and incorporate a limited number of physical processes. Nevertheless, EMICs have shown to be invaluable in modern climate research. For example, they have been used to explain low-frequency variability in the climate system, can cover wide value ranges in parameter space and have been used to extend climate projections for future climate (see, e.g., Brovkin et al., 2002; Joos et al., 2001; Weaver et al., 2001).

A host of EMICs are currently used in the literature, ranging from energy balance models with prescribed atmospheric dynamics to 3-D atmosphere and ocean models with interactive physics and dynamics (e.g., Smith et al., 2008; Farneti and Vallis, 2009). Here we report on the new global SPEEDO model which can be regarded as the successor of the ECBILT-CLIO model (Opsteegh et al., 1998; Goosse and Fichefet, 1999) and which fills a gap between EMICs, with often specified simplified dynamics, and state-of-the-art global climate models. ECBILT is a quasi-geostrophic atmosphere model with only 3 layers and limited resolved or parameterised physics. It has been used extensively in climate studies, for instance as part of the LOVECLIM earth system model (e.g., Roche et al., 2007). One of the drawbacks of the ECBILT model is that the quasi-geostrophic approximation breaks down in the tropics. Also, the prescribed clouds and the adjustment in the fresh water flux limit the application of

Published by Copernicus Publications on behalf of the European Geosciences Union. 
the model. Here we report on the SPEEDO (Speedy-Ocean) model that has a primitive equation dynamical core in the atmosphere and fully interactive physics. Therefore, it does not have the limitations of ECBILT. However, its parameterisations are simplified (Molteni, 2003) and the resolution is coarse to allow for long runs.

The atmospheric model used in SPEEDO forced by observed surface conditions and coupled to a global slab ocean model and to a basin-scale ocean model has been used in many studies already (e.g., Molteni, 2003; Hazeleger and Haarsma, 2005; Hazeleger et al., 2005; Bracco et al., 2005; Kucharski et al., 2006; Breugem et al., 2007). In SPEEDO V1.0 a basin-scale ocean model was used. In this paper we describe the fully global SPEEDO V2.0 model and present a number of integrations of pre-industrial climate, current climate and projected future climate changes in order to validate the model, to compare it with state-of-the-art climate models and to demonstrate potential applications.

\section{Model description}

The SPEEDO model consists of a global atmosphere model, Speedy, a global ocean and sea-ice model, CLIO, and a simple land-surface model. The current version does not include biogeochemical modules. Both the atmosphere and ocean components are based on the primitive equations. The parameterisations in Speedy are simplified and described by Molteni (2003), with some modifications as described by Hazeleger et al. (2005). The parameterisation package has been specially designed to work in models with just a few vertical levels, and is based on the same physical principles adopted in the schemes of state-of-the art GCMs.

The parameterised atmospheric processes include largescale condensation, convection, clouds, short and long wave radiation, surface fluxes and vertical diffusion. The largescale condensation is implemented as a relaxation of specific humidity to a reference profile. The convection scheme is a simplified version of the mass-flux scheme developed by Tiedke (1993). The scheme is applied at grid points where saturation moist static energy decreases between the planetary boundary layer (PBL) and the upper troposphere and the relative humidity in the PBL exceeds a threshold. Entrainment in the convective updrafts occurs in the lower half of the troposphere above the PBL and detrainment occurs only at the cloud-top level. The properties of clouds are defined diagnostically from values of relative and specific humidity in the tropospheric air column above the PBL. The short wave radiation parameterisation uses a visible and a nearinfrared band and includes absorption by ozone in the stratosphere and reflection at the top of clouds and the surface. The long wave radiation parameterisation uses four bands: one for the infrared window, for the strong absorption by $\mathrm{CO}_{2}$, for the weak and moderate absorption by water vapour, and for the strong absorption by water vapour. The effect of a varying $\mathrm{CO}_{2}$ concentration is parameterised by changing the long wave absorption coefficient of the $\mathrm{CO}_{2}$ band. For both the short and long wave parameterisation, the transmission of each model layer depends on its mass, specific humidity and cloud cover. Aerosols, volcanoes, tropospheric ozone and other greenhouse gases are currently not represented in the model but can be implemented by varying the transmission of the layers. The tropopause is represented in SPEEDO by keeping the specific humidity and the air temperature gradient in the two upper model levels equal to zero. This ensures that the stability increases in the upper two levels of the model. We refer to Molteni (2003) and Hazeleger et al. (2005) for the details on the numerics and parameterisations.

The spectral triangular truncation in SPEEDO is at total wave number 30 (T30) and there are 8 layers in the vertical. The advection scheme used in the original Speedy model does not conserve energy, tracers and dry air mass. In a coupled model these losses can result in a climate drift. Therefore a correction was added to the advection scheme of SPEEDO that compensates the loss of tracers and dry air mass. Furthermore, the model was tuned such that the energy loss only affects the energy budget at the top of the atmosphere and does not cause drift in the ocean and land models. For estimating the parameters the method of Severijns and Hazeleger (2005) has been applied to the atmosphere model. During the tuning the CLIO ocean model was replaced by a sea surface temperature (SST) climatology for the present day climate. To keep the surface heat flux budget closed, a term was added to the cost function that increases rapidly when this budget deviates from zero.

The ocean model used in SPEEDO is the CLIO model. We refer to Goosse and Fichefet (1999) for details on this model. The CLIO model has 20 layers, uses a z-vertical coordinate and has a horizontal resolution of about $200 \mathrm{~km}$. The LIM sea ice model is incorporated in CLIO. For the isopycnal mixing the parameterisation by Gent and McWilliams (1990) is used with a diapycnal diffusivity of $200 \mathrm{~m}^{2} \mathrm{~s}^{-1}$. The parameterisation for vertical mixing in CLIO is derived from the Mellor and Yamada 2.5 level model (Mellor and Yamada, 1982). Strong convection is parameterised in a manner similar to Marotzke (1991) by increasing the vertical diffusivity whenever the density profile is unstable. In the initial coupled experiments with SPEEDO, the model was not able to maintain an Atlantic meridional overturning circulation (AMOC). To improve this, the background vertical diffusivity was increased in the upper nine model levels which correspond to the upper $150 \mathrm{~m}$ of the ocean. The coefficient of vertical diffusivity varies between a background value of $10^{-5} \mathrm{~m}^{2} \mathrm{~s}^{-1}$ to $10^{-4} \mathrm{~m}^{2} \mathrm{~s}^{-1}$ in the upper $30 \mathrm{~m}$ and below $2500 \mathrm{~m}$. A parameterisation for down-sloping currents along continental boundaries is included in CLIO.

The land model consists of a bucket model with three soil layers and up to two snow layers. It includes a simplified hydrology in which the run off is collected in river basins and drained into the ocean at specific locations of major river 
outflows. The freezing and melting of soil moisture is taken into account. Each bucket has a fixed maximum soil moisture capacity. The land surface albedo is prescribed using a monthly climatology.

The atmosphere, land, and ocean/sea-ice components of SPEEDO run each on a single CPU and exchange data via a coupler. In order to use more than three CPUs one or more of the component models needs to be parallellised. The coupler is implemented as a library that is linked to each component model. This ensures that the coupling workload is evenly distributed between the CPUs and that the coupler's performance scales well. The atmosphere and land models use the same Gaussian latitude-longitude grid. The ocean and sea-ice model uses a curvilinear grid that is designed to avoid small grid cell dimensions near the North pole. This enhances the numerical stability of the model which makes it possible to use a much larger time step and increases its computational efficiency. A first order conservative method is used to regrid data between the grids of the atmosphere and ocean models. The outflow of each river in the land model, is transferred to the ocean model where it is distributed over ocean grid points close to the river's outlet. The coupled model runs without any flux correction.

Although the resolution of the SPEEDO model is relatively coarse, we will show that it is sufficient to resolve the main phenomena of the general circulation in the atmosphere and ocean except for the El Niño Southern Oscillation (ENSO). The model is sufficiently fast to perform runs of $O\left(10^{4}\right)$ years on desktop computers. For example, it takes less than $20 \mathrm{~min}$ to simulate one year on an Intel Core 2 Duo E6850 CPU at $3 \mathrm{GHz}$. All runs discussed in this paper have been obtained from runs performed on a single workstation.

\section{Results}

Several simulations were performed with the SPEEDO model to compare it with observed climate data and results from state-of-the-art climate models. An overview of the runs is given in Fig. 1. The model was spun up for a period of 2000 years under pre-industrial conditions. This run was started from the final state of a 4000-year long test run under present day conditions in which some of the model parameters were being varied. The final state of the spin up run was used as the initial condition in the year 1800 for the experiments presented in this paper. First, a 1000-year control run was done also under pre-industrial conditions to assess the stability of the model. Second, a five member ensemble of 300-year long experiments with perturbed initial condition was done with 19th and 20th century conditions and a scenario for the 21 st century. The results of this ensemble are compared to observed climate data and CMIP3 model results (Meehl et al., 2007). Hereafter, a 200-year $\mathrm{CO}_{2}$ doubling experiment was done to determine the climate sensitivity of SPEEDO. Finally, a 1200 -year scenario exper-

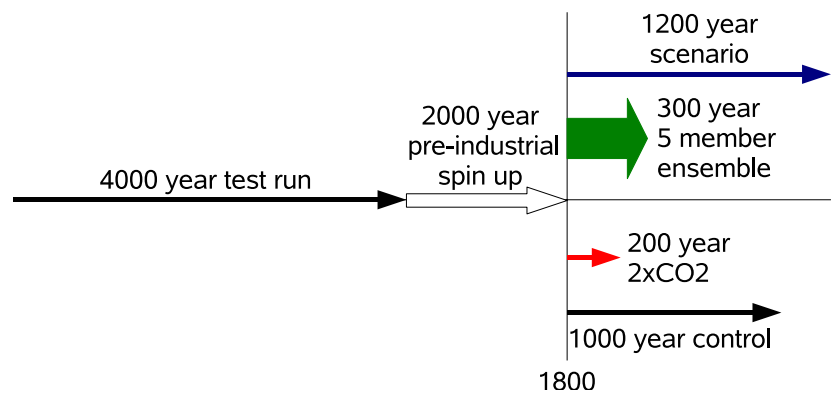

Fig. 1. Schematic overview of the SPEEDO runs.

iment was done with an enhanced prescribed time-varying $\mathrm{CO}_{2}$ concentration to determine the model's transient climate response. In the following sections we present the results of these experiments.

\subsection{Control simulation}

To verify that the model was in equilibrium after the spin up, we performed a 1000-year long control simulation in which the equivalent $\mathrm{CO}_{2}$ concentration was set to 261 parts per million (ppm) and the solar forcing was kept constant. We focus on the energy budget and the total heat and fresh water content in the ocean. In the case of a climate in equilibrium these should be constant. The global mean value, standard deviation and drift - the mean over the last 100 years minus the mean over the first 100 years - was computed for the following annual mean quantities: the top-of-the-atmosphere (TOA) energy budget, the surface energy budget, the two meter air temperature $\left(T_{2 \mathrm{~m}}\right)$, the ocean heat content and salinity and the sea ice volume. The results are shown in Table 1. For all quantities the drift is smaller than the standard deviation. The difference between the TOA and surface energy budgets is caused by the energy loss of $1.5 \mathrm{Wm}^{-2}$ in the atmosphere model. Since the parameterisations for vertical processes in SPEEDO conserve energy, the advection scheme, the correction for the loss of dry air and tracer mass, or other components cause this energy loss. Despite this loss of energy the model is stable. The net surface energy budget is positive instead of zero because the latent heat difference between snow and rain is not taken into account in the model. As a result, the heat that is extracted from the land surface to melt snow is not compensated by a latent heat difference when snow instead of rain falls on the land surface. The energy budget of the model is closed because this latent heat is released in the atmosphere when snow is formed. The lack of drift in the $T_{2 \mathrm{~m}}$ and the small changes in the ocean temperature and salinity show that the underlying land and ocean/sea-ice models are in equilibrium and no flux correction is needed. The time series of the global mean ocean temperature and salinity shown in Fig. 2 confirm this. Note that the salinity varies by a small amount because CLIO is a constant volume 

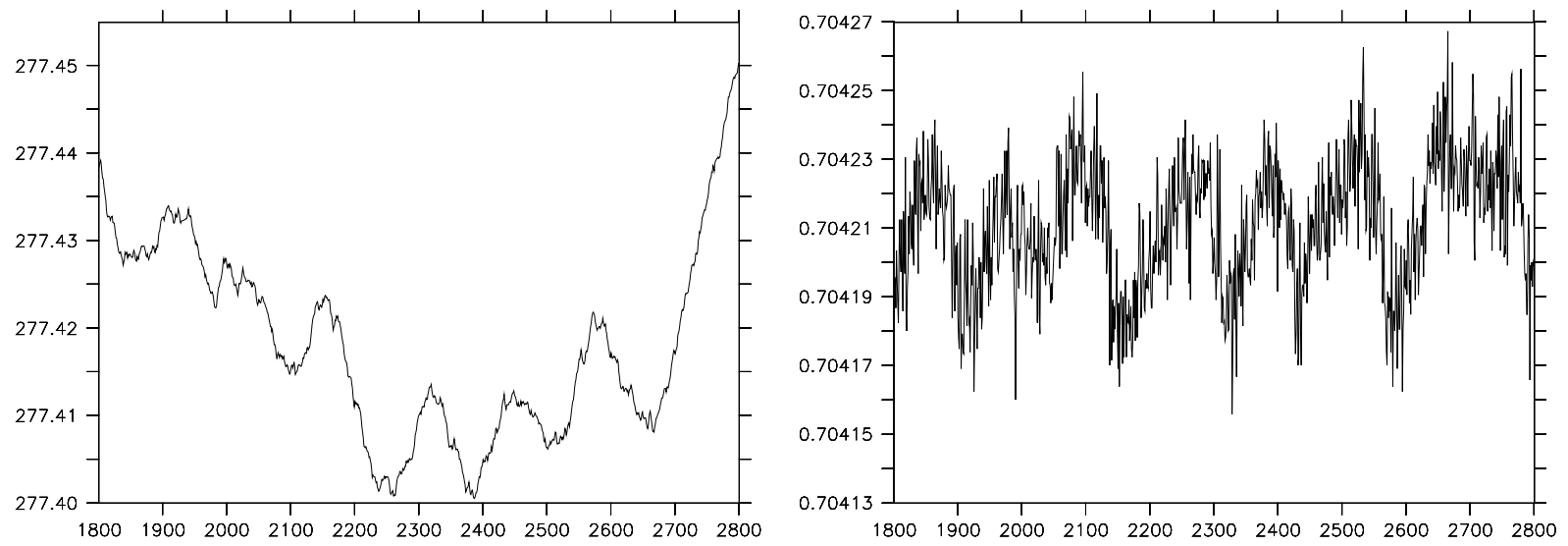

Fig. 2. The global annual mean ocean temperature in K (left) and salinity in PSU (right) in the SPEEDO control run. An offset of 34 PSU has been subtracted from the salinity data for this plot.

Table 1. The time mean value, the standard deviation and the drift of the TOA and surface energy budgets, the global mean two meter temperature, the global mean ocean temperature and salinity and the total sea ice volume. The drift is defined as the mean over the last 100 years minus the mean over the first 100 years.

\begin{tabular}{llllc}
\hline Quantity & Mean value & Standard deviation & Drift & Unit \\
\hline TOA budget & 2.491 & $1.83910^{-1}$ & $1.05210^{-2}$ & $\mathrm{Wm}^{-2}$ \\
Surface budget & 1.053 & $1.84110^{-1}$ & $1.35210^{-2}$ & $\mathrm{Wm}^{-2}$ \\
$T_{2 \mathrm{~m}}$ & 285.3 & $2.52610^{-1}$ & $-6.34210^{-2}$ & $\mathrm{~K}$ \\
Ocean temperature & 277.3 & $1.09210^{-2}$ & $-7.09210^{-3}$ & $\mathrm{~K}$ \\
Salinity & 34.70 & $1.85610^{-5}$ & $1.14410^{-5}$ & PSU \\
Sea ice volume & 15.37 & 1.436 & 1.018 & $10^{12} \mathrm{~m}^{3}$ \\
\hline
\end{tabular}

ocean model that is forced by a global mean fresh water flux which can deviate from zero on small time scales. On time scales of centuries and longer the fresh water budget is closed in SPEEDO. The data on the total sea ice volume shows that the sea ice model is also in equilibrium.

\subsection{0th and 21st century ensemble simulations}

\subsubsection{Mean state}

In order to compare SPEEDO with 20th century climate data (using primarily atmospheric reanalysis data; Kalnay et al., 1996) and data from CMIP3 models, a five member ensemble with perturbed initial condition was run for the period 1800-2100. The initial condition of each member was perturbed by adding a Gaussian noise term with a standard deviation of $0.1 \mathrm{~K}$ to the air temperature. The $\mathrm{CO}_{2}$ concentration follows the observed historical $\mathrm{CO}_{2}$ concentration from 1800 to 2000. From 2000 until 2100 it follows approximately the SRES A2 scenario (Nakicenovic et al., 2000). These $\mathrm{CO}_{2}$ concentrations are obtained from the UVic model (Montenegro et al., 2007) which contains a carbon cycle such that slight deviations from the A2 scenario occur. The model's climatology and budgets were computed for the 41-year time period from 1960 to 2000 in order to validate the 20th century model climate.

The global mean TOA and surface radiation and heat fluxes and budgets in the ensemble mean from 1960 to 2000 are compared to data from Kiehl and Trenberth (1997) and Trenberth et al. (2009) in Table 2. Both the TOA short and long wave radiation fluxes in SPEEDO are lower than in estimates from observations. This implies that the planetary albedo in SPEEDO is higher than implied by observations. This is compensated by an increased trapping of long wave radiation. The surface short wave radiation flux is high and in combination with the low TOA short wave radiation budget we conclude that the absorption of short wave radiation by the atmosphere in the model is too low. Most of the excess surface short wave radiation is compensated by the surface long wave radiation. The surface latent heat flux in SPEEDO is in good agreement with the data. The sensible heat flux is in agreement with the 1997 data but higher than the 2009 data. The net TOA budget is $2.5-3.4 \mathrm{Wm}^{-2}$ larger than the observations. A large part of this difference corresponds to 
Table 2. The ensemble mean global mean radiation and heat flux budgets at the top of the atmosphere and the surface in the SPEEDO model compared to the results published by Kiehl and Trenberth (1997) and Trenberth et al. (2009). Positive values indicate downward fluxes.

\begin{tabular}{lrrr}
\hline Flux or budget in $\mathrm{Wm}^{-2}$ & SPEEDO & Kiehl and Trenberth (1997) & Trenberth et al. (2009) \\
\hline TOA short wave radiation & 227.3 & 235 & 239.4 \\
TOA long wave radiation & -223.9 & -235 & -238.5 \\
Surface short wave radiation & 173.6 & 168 & 161.2 \\
Surface long wave radiation & -69.0 & -66 & -63 \\
Surface latent heat & -78.3 & -78 & -80.0 \\
Surface sensible heat & -24.5 & -24 & -17 \\
TOA budget & 3.4 & 0 & 0.9 \\
Surface budget & 1.9 & 0 & 0.9 \\
\hline
\end{tabular}

the energy that is required to compensate for the energy loss in the atmosphere model (see Sect. 3.1). The net surface budget in the control run is slightly larger than the values given by Kiehl and Trenberth (1997) and Trenberth et al. (2009).

The vertical global annual mean air temperature, $T_{\mathrm{a}}$, profile is shown in Fig. 3. Comparing this profile with that for the reanalysis data of (Kalnay et al., 1996), we see that $T_{\mathrm{a}}$ in SPEEDO is in good agreement with the reanalysis data in the lower troposphere, is too low in the middle troposphere with a maximum deviation of $1 \mathrm{~K}$ at $500 \mathrm{hPa}$, and is upto $5 \mathrm{~K}$ too high in the upper troposphere. Note that in SPEEDO $T_{\mathrm{a}}$ is constant above $100 \mathrm{hPa}$ due to the way in which the tropopause is represented in the model (see Sect. 2).

To illustrate the general atmospheric circulation in SPEEDO we compare the ensemble mean of the zonal wind at $925 \mathrm{hPa}$ with reanalysis data in Fig. 4. The spatial structure of the zonal wind field resembles the reanalysis data fairly well. The annual zonal mean zonal wind in the southern storm track in SPEEDO is $8.7 \mathrm{~ms}^{-1}$ which is less than the value of $10.6 \mathrm{~ms}^{-1}$ in the reanalysis data and the storm track is located about $10^{\circ}$ too far to the north. The Indian monsoon occurs at the correct location in the model but the maximum zonal wind speed of $11 \mathrm{~ms}^{-1}$ is too low compared to the value of $17 \mathrm{~ms}^{-1}$ in the reanalysis data.

As a further illustration, the zonal eddy component at $500 \mathrm{hPa}$ is shown in Fig. 5 for December-February (DJF) and June-August (JJA). In DJF, when the atmospheric dynamics dominate the circulation characteristics, the zonal eddy component of SPEEDO shows the same spatial structure as the reanalysis data but the extreme values are too low. In JJA the resemblance is not as good but in this period the zonal eddy component is weak and local feedbacks tend to affect the circulation. It is noteworthy that these circulation components are comparable and in many aspects improved compared to an earlier atmosphere only version of the model (Molteni, 2003).

Figure 6 compares the cloud cover in SPEEDO with data from ISCCP (Rossow and Schiffer, 1991). The cloud cover over sea ice and land is generally in good agreement with the

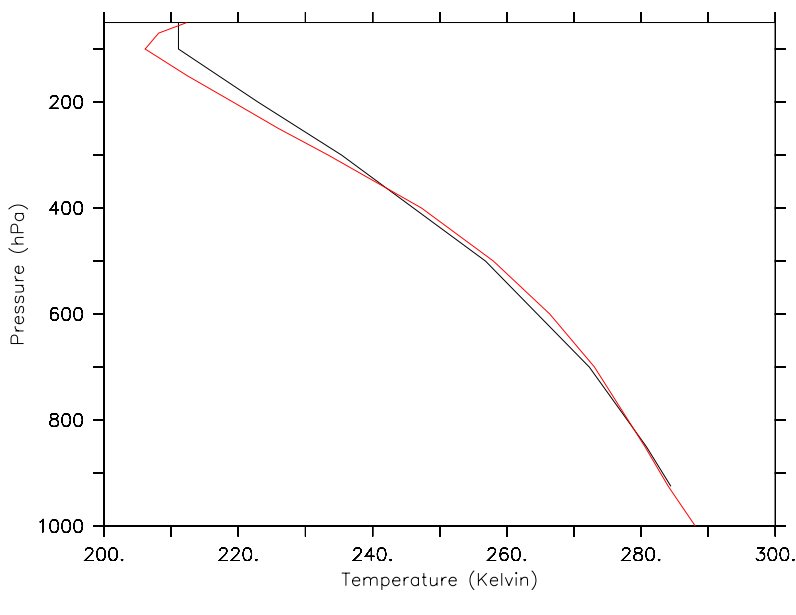

Fig. 3. The global annual mean air temperature profile in $\mathrm{K}$ from SPEEDO (black) and from the reanalysis data from Kalnay et al. (1996) (red).

data. Over sea this is not the case. The cloud cover is too low in the Tropics and the storm track areas and there are too many clouds in the subsidence areas in the northern Tropical Pacific and the North and South Atlantic. A part of the cloud cover problems in the Tropics is due to the fact that the cloud cover is diagnosed from the precipitation. However, these biases do not strongly affect the surface energy budget, as shown in the previous section.

The precipitation in SPEEDO is shown in Fig. 7. The cold tongue in the sea surface temperature (SST) along the equator in the Pacific causes a double Intertropical Convergence Zone in the boreal winter and at the same time causes the errors in the tropical cloud cover. The figure also shows that the model has too much precipitation in tropical Africa and the Amazon and too little rain over tropical Atlantic and the warm pool. These are typical features of coarse resolution climate models (see, e.g., Dai et al., 2001; Schmidt et al., 2006; Johns et al., 2006). 

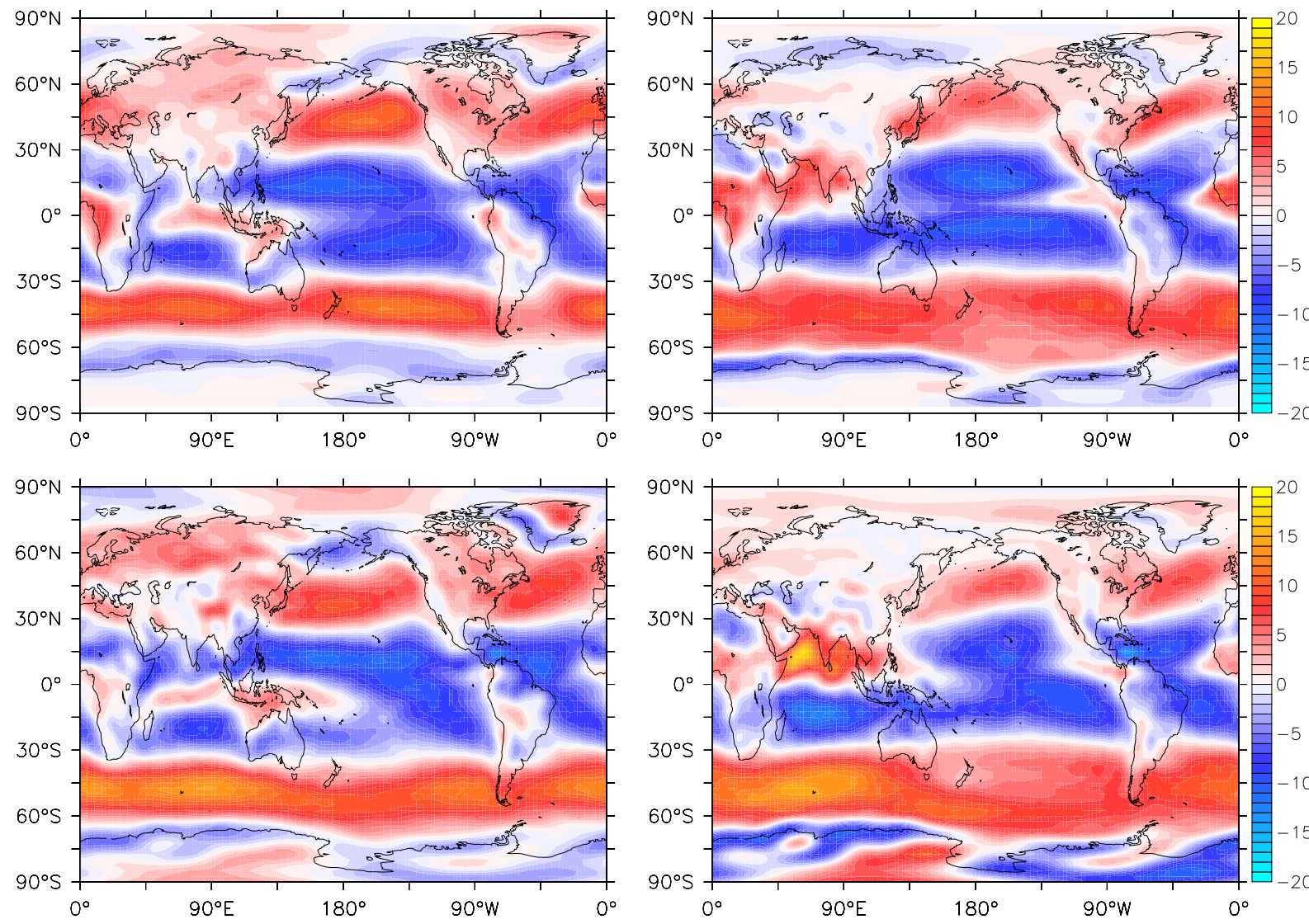

Fig. 4. The zonal wind at $925 \mathrm{hPa}$ in $\mathrm{ms}^{-1}$ in DJF (left) and JJA (right) of the mean of the SPEEDO ensemble (top) and the reanalysis data from Kalnay et al. (1996), (bottom).

SPEEDO is a coupled atmosphere-ocean model and the ocean can evolve freely. The difference between the ensemble mean of the annual mean SST in SPEEDO and observations (Stephens et al., 2001) is shown in Fig. 8. The SSTs in the Tropics, in the Arctic and near Antarctica are slightly too high. The boundary current areas and the subtropical stratocumulus areas near the coast are also too warm. In the remaining area the SST is too low, especially in the South Atlantic. These biases are within the spread of the CMIP3 multi-model ensemble (Meehl et al., 2007).

For the ocean, the meridional overturning circulation is important as it transports heat, fresh water and tracers within the earth system. The ensemble mean Atlantic meridional overturning circulation (AMOC) averaged from 1960 to 2000 is shown in the left panel of Fig. 9. The upper cell is slightly stronger than $8 \mathrm{~Sv}\left(1 \mathrm{~Sv}=10^{6} \mathrm{~m}^{3} \mathrm{~s}^{-1}\right)$. This is approximately $3 \mathrm{~Sv}$ weaker than under pre-industrial conditions in the control run and about $8 \mathrm{~Sv}$ too weak compared to estimates of e.g. Cunningham et al. (2007). This is most likely associated with a low production of North Atlantic Deep Water (NADW) due to the lack of convection in the Labrador Sea. This is illustrated by Fig. 10 which shows the maximum of the ensemble mean of the monthly mean mixed layer depth in SPEEDO. In addition, the weak AMOC above $60^{\circ} \mathrm{N}$ suggests that exchange between the Arctic and North Atlantic oceans is insufficient. The global meridional overturning circulation (GMOC) is shown in the right panel of Fig. 9. The GMOC is dominated by Ekmann-driven cells in the upper ocean, an Antarctic Bottom Water (AABW) cell and a North Atlantic Deep Water cell. Note that the overturning does not display a strong, spurious Daecon cell in the Southern ocean because the isopycal transport formulation by Gent and McWilliams (1990) is used in CLIO (Danabasoglu and McWilliams, 1995). The maximum strength of the AABW cell of $12 \mathrm{~Sv}$ is in good agreement with observational data of the production of Antarctic Bottom Water found by Orsi et al. (1999).

The time mean atmospheric, global ocean, Atlantic and Indo-Pacific heat transports of all ensemble members are shown in Fig. 11. Inferences of observations of these quantities depends on inverse modelling. Also, surface fluxes from atmospheric reanalysis can be used. The atmospheric heat transport in SPEEDO was computed from the TOA and surface fluxes after removing the global mean energy loss in the atmosphere from the TOA fluxes. The atmospheric heat transport in SPEEDO is close to the reanalysis data from Trenberth and Caron (2001). The global ocean heat transport in the Northern Hemisphere is too small but in the 

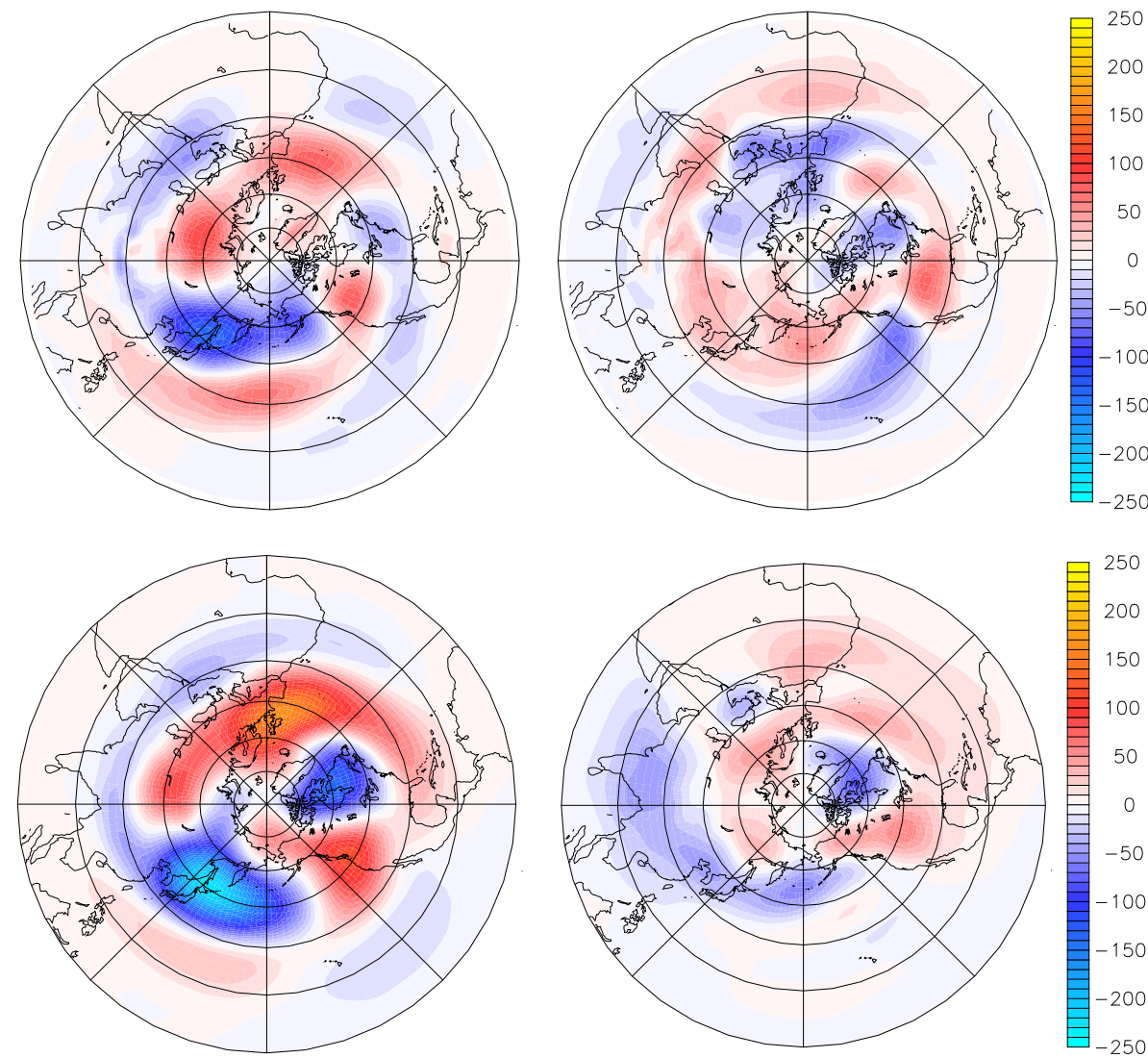

Fig. 5. The zonal eddy component of the geopotential height at $50 \mathrm{hPa}$ in $\mathrm{m}$ in DJF (left) and JJA (right) of the mean of the SPEEDO ensemble (top) and the reanalysis data from Kalnay et al. (1996), (bottom).
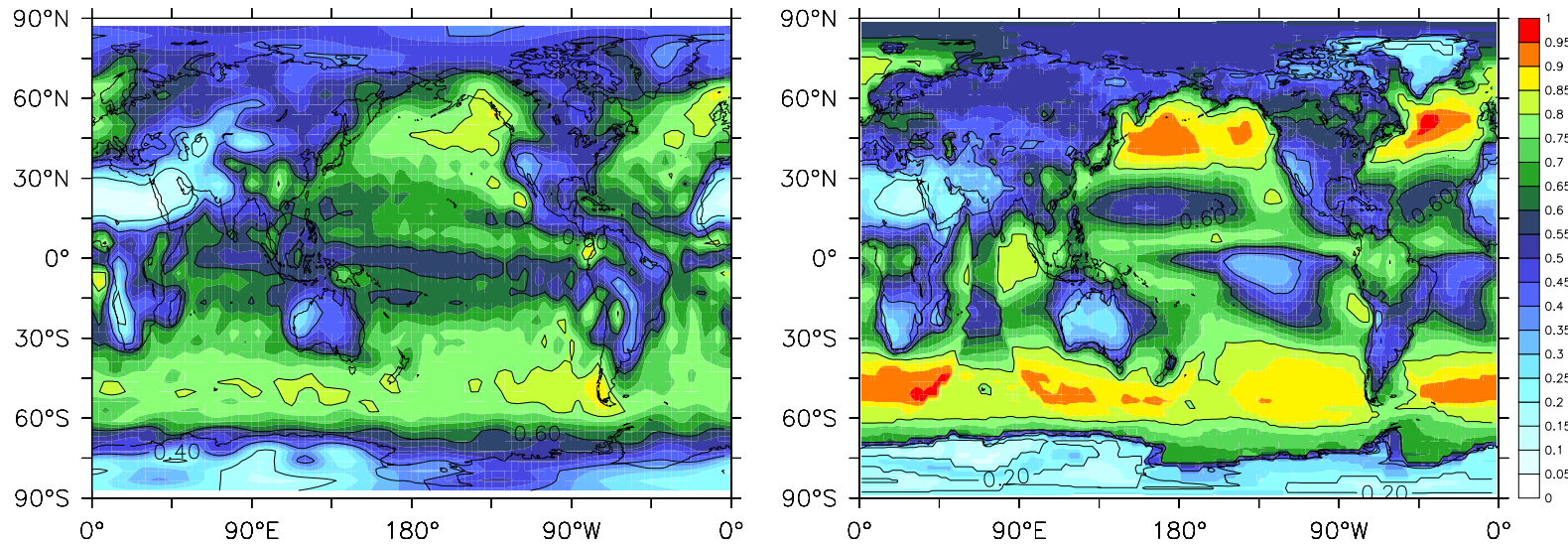

Fig. 6. The annual mean cloud cover fraction for the mean of the SPEEDO ensemble (left) and according to Rossow and Schiffer (1991), (right).

Southern Hemisphere falls within the uncertainty in the reanalysis data. The Atlantic heat transport is too low as can be expected from the weak AMOC. The heat transport in the Indo-Pacific shows that the model performs well outside the Atlantic. The model's internal variability causes the Atlantic heat transport to vary by $0.05 \mathrm{PW}$.
The monthly ensemble mean sea ice cover in the Arctic and Antarctic for March and September is compared to the sea ice cover data from Cosimo (2008) in Fig. 12. It is evident that in both hemispheres the sea ice cover at the end of the summer is too low. The winter sea ice cover is slightly too large. Experiments with an increased sea ice surface 

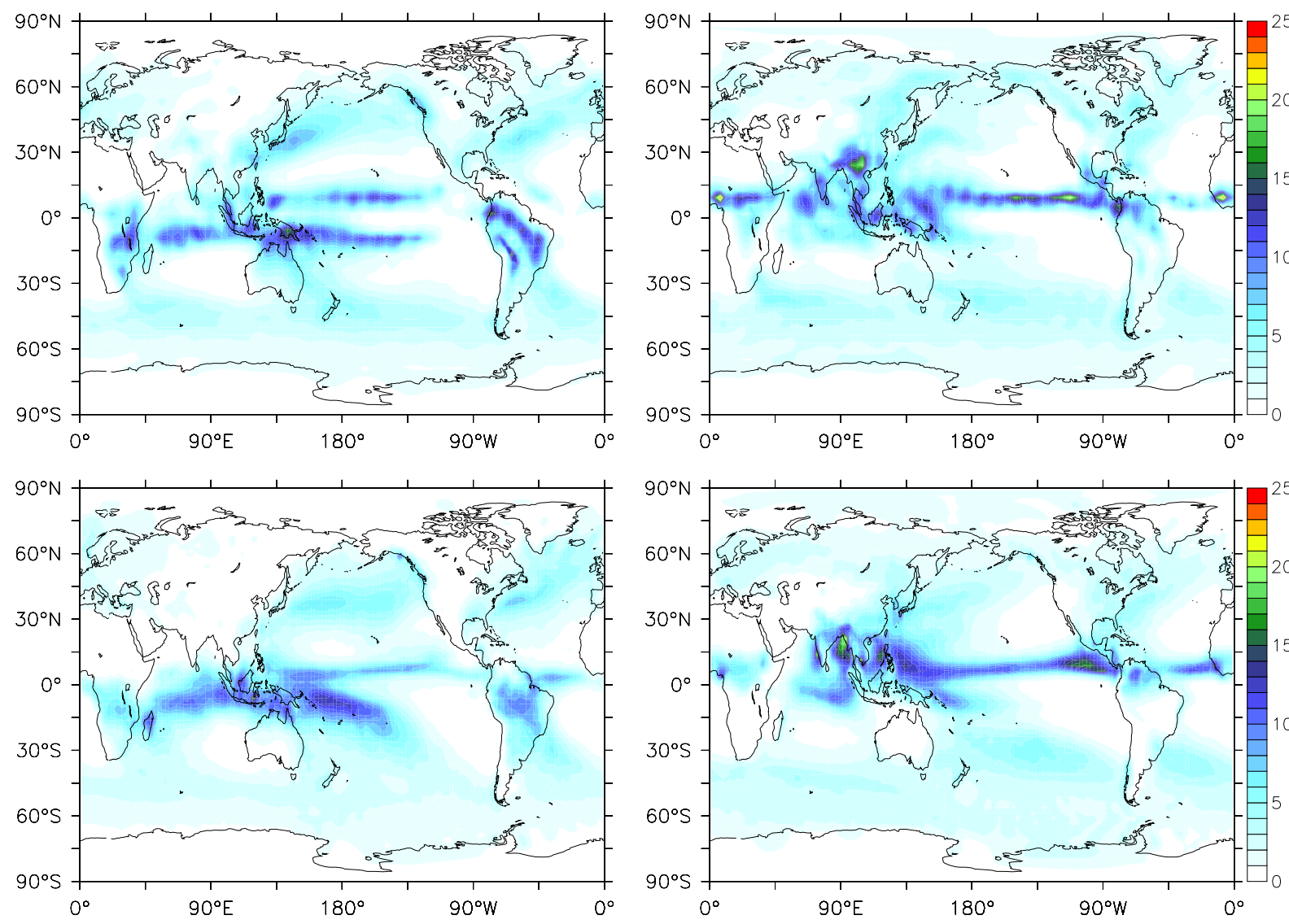

Fig. 7. The total precipitation in $\mathrm{mmday}^{-1}$ in DJF (left) and JJA (right) for the mean of the SPEEDO ensemble (top) and from Xie and Arkin (1996), (bottom).

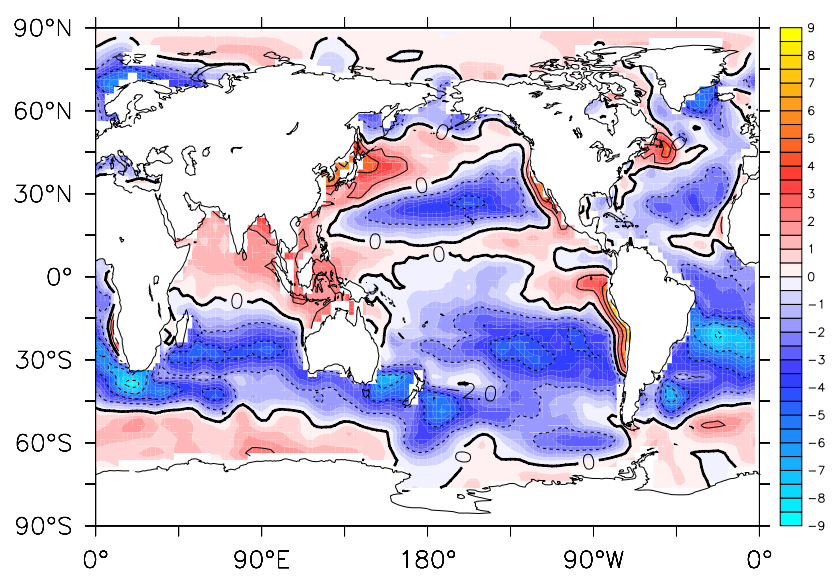

Fig. 8. The difference between the ensemble mean of the annual mean SST in SPEEDO and the SST according to Stephens et al. (2001) in K. albedo and increased cloud albedo in the Arctic and Antarctic showed no improvements. Note that in SPEEDO the southern part of the Labrador Sea is covered by sea ice in the winter season. This prevents that deep convection occurs in this area and is an additional cause of the weak AMOC in the model. The reason for the large seasonal cycle in the sea ice cover seems to be the fast growth in the winter season. We note that the seasonal cycle in $T_{2 \mathrm{~m}}$ over land is also too large in SPEEDO which suggests the main cause is in the atmosphere model.

\subsubsection{Variability}

The main patterns of inter-annual variability in the Northern Hemisphere are the Pacific North American (PNA) (Wallace and Gutzler, 1981) and the North Atlantic Oscillation (NAO) (Hurrell, 1995) patterns. The regression coefficient of the PNA index with the Z500 anomalies and of the NAO index with the mean sea-level pressure (MSLP) anomalies for SPEEDO and for the NCEP-NCAR Reanalysis (Kalnay et al., 1996) data from 1960 to 2001 are shown in Fig. 13. The NAO index is computed here as the difference of the MSLP anomalies in the area $70^{\circ} \mathrm{W}$ to $10^{\circ} \mathrm{W}$ and $55^{\circ} \mathrm{N}$ to $77^{\circ} \mathrm{N}$ and 

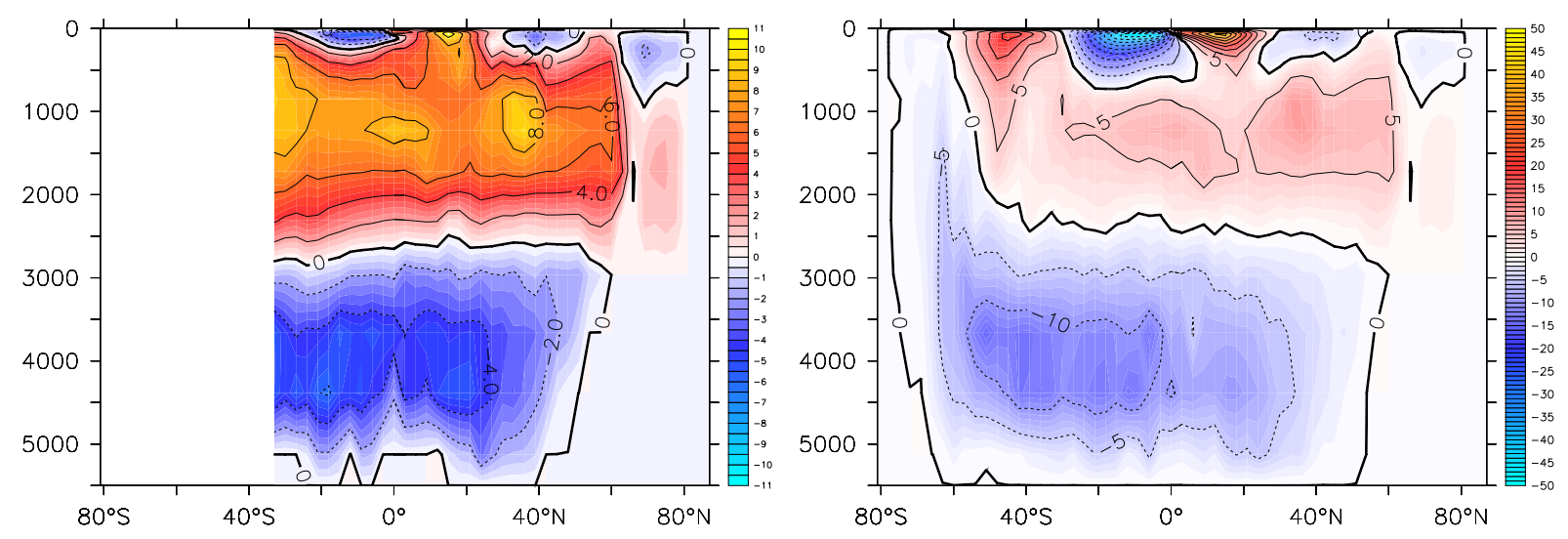

Fig. 9. The ensemble mean Atlantic (left) and global (right) meridional overturning circulation in Sv in SPEEDO.

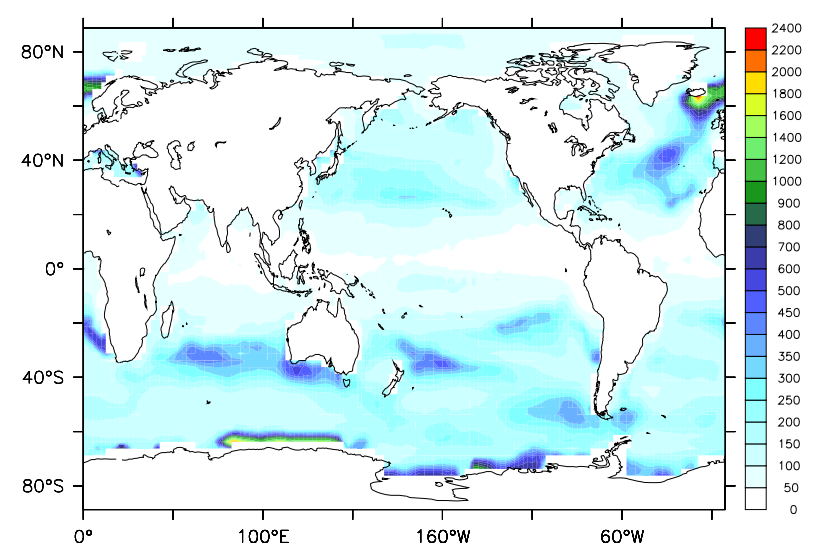

Fig. 10. The maximum of the ensemble mean of the monthly mean mixed-layer depth in SPEEDO in $\mathrm{m}$.

the area $70^{\circ} \mathrm{W}$ to $10^{\circ} \mathrm{W}$ and $35^{\circ} \mathrm{N}$ to $45^{\circ} \mathrm{N}$. The anomalies of each ensemble member were computed by subtracting the ensemble mean in order to remove the global warming signal. The regression was computed for the data of all ensemble members. The PNA pattern displays a well-known wave train, indicating that the response to tropical convection is good. The NAO pattern shows the familiar dipole pattern. The pattern is slightly shifted to the west compared to observations.

The variability in the tropical Pacific is far too weak compared to observations (McPhaden et al., 1998) and therefore we do not show the El Niño Southern Oscillation (ENSO) index. For example, the standard deviation of the monthly mean NINO3.4 index is $0.23 \mathrm{~K}$ which is much smaller than the standard deviation of $0.91 \mathrm{~K}$ in the data of Reynolds et al. (2002) and the power spectrum of the NINO3.4 index has no peak at the time scales corresponding to the ENSO phenomenon. This is most likely the result of the coarse resolution of the model (van Oldenborgh et al., 2005). In experiments with Speedy coupled to a linear ENSO model, variability did occur in the tropical Pacific.
At multidecadal time scales, an interhemispheric dipole pattern is found in observations in the Atlantic: the Atlantic Multidecadal Oscillation (AMO) (Sutton and Hodson, 2005). The pattern of the AMO in SPEEDO is shown in the upper panel of Fig. 14. The pattern was computed using the SST anomalies of individual members with respect to the ensemble mean SST. In this manner the global mean warming trend in the SST as the result of the increasing $\mathrm{CO}_{2}$ concentration was removed. We regressed the SST anomalies onto an AMO index that is defined as the mean SST anomaly from $25^{\circ} \mathrm{N}$ to $60^{\circ} \mathrm{N}$ and from $75^{\circ} \mathrm{W}$ to $7^{\circ} \mathrm{W}$. Only statistically significant data with $r^{2}>0.1$ is shown. The AMO pattern for the NCEP-NCAR reanalysis (Kalnay et al., 1996) for the period from 1960 to 2000 after detrending is shown in the center panel of Fig. 14. The maximum amplitude of the AMO pattern in SPEEDO is located between $45^{\circ} \mathrm{N}$ and $60^{\circ} \mathrm{N}$ and between $30^{\circ} \mathrm{N}$ and $60^{\circ} \mathrm{N}$ in the reanalysis data. It can be seen in the lower panel of Fig. 14 that the AMO index in SPEEDO has a red noise spectrum except at centennial time scales. The variability at this time scale is most likely related to the variability in the Arctic sea ice volume because in winter the Arctic sea ice near Canada extends south of $60^{\circ} \mathrm{N}$. The similarity of the AMO power spectrum with the power spectrum of the Arctic sea ice volume in Fig. 17 confirms this. Unlike some other models (Knight et al., 2005), the AMO index is only weakly correlated to the anomalies in the AMOC with a maximum correlation of about 0.5.

The time series of the maximum strength of the AMOC and its power spectrum are shown in Fig. 15. An AR(1) spectral analysis of the AMOC time series shows that the AMOC has a red noise spectrum (with more than $95 \%$ confidence).

The Antarctic sea ice volume in SPEEDO varies strongly at centennial time scales (see Fig. 16). To study this variability, we analysed the data from the 1000-year control run because the variability remains present during the complete control run while in the ensemble it disappears when the sea ice melts due to global warming. The total sea ice volume in the Arctic (see Fig. 16) varies only slightly on centennial 

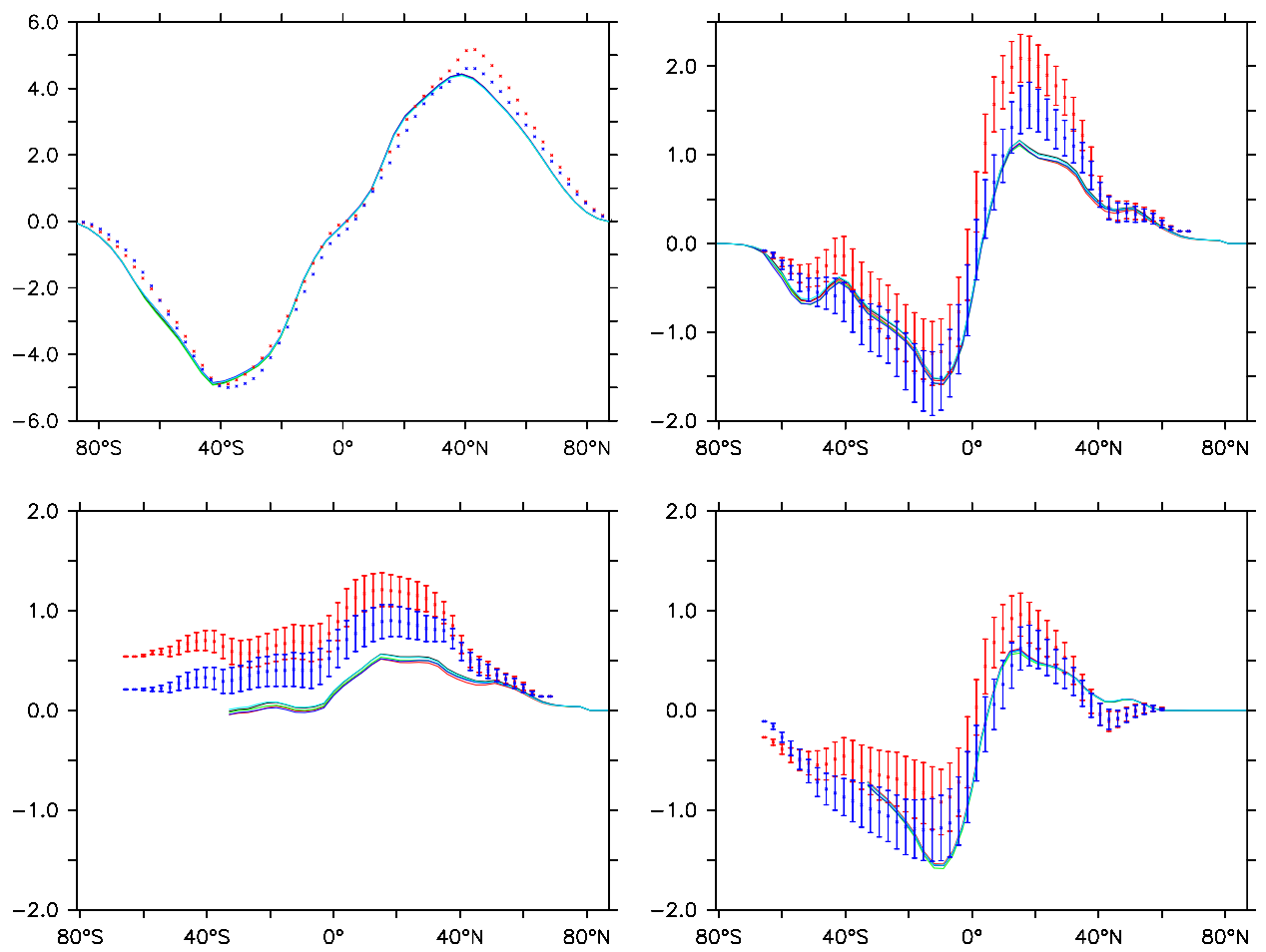

Fig. 11. The global atmospheric (upper left), global ocean (upper right), Atlantic ocean (lower left), and Indo-Pacific ocean (lower right) heat transport in PW for each member of the SPEEDO ensemble (solid lines). Positive values indicate northward transport. The reanalysis data by Trenberth and Caron (2001) for the NCEP-NCAR (red) and ERA15 (blue) are shown with crosses. The ocean heat transports are derived using an inverse modelling method. For these data the one standard deviation uncertainty in the inverse modelling results are indicated by error bars.

time scales. The power spectrum of the annual mean Antarctic sea ice volume has a peak at time scales of 100-200 years (see Fig. 17). An AR(1) spectral analysis shows that this peak is significant with more than $95 \%$ confidence in both hemispheres. Note that a similar peak is not present in the power spectrum of the AMOC.

The regression coefficient of the Antarctic sea ice volume with the strength of the GMOC is shown in Fig. 18. This regression suggests that the oscillations in the sea ice volume are caused by a local interaction of the sea ice with the ocean. This is confirmed by regressions of the Antarctic sea ice volume with the sea water temperature at various levels in the ocean model (not shown). The regression coefficient of the sea ice volume with the AMOC is nowhere statistically significant. The mechanism of this variability is associated with interaction between sea ice, ocean convection, and vertical mixing. In short, while ice volume grows, heat is stored in the deeper layers. This heat is released when the water column becomes unstable and causes the sea ice to retreat. A detailed analysis of this variability is beyond the scope of this paper.
Finally, we show the long-term trend in SPEEDO, forced by the growing greenhouse gas concentrations in the 20th century. The global mean two meter air temperature in the SPEEDO ensemble is compared to those from the CMIP3 SRES A2 multi-model ensemble for the period 2000-2100 (Fig. 19). SPEEDO starts close to the mean of the CMIP3 ensemble but warms slightly faster. However, SPEEDO remains within one standard deviation from the mean of the CMIP3 ensemble. Note that SPEEDO follows the observed warming in the mid-20th century, the reduced warming afterward and steep warming from the late 20th century on.

\section{3 $\mathrm{CO}_{2}$ doubling experiment}

In order to study the models climate sensitivity a $\mathrm{CO}_{2}$ doubling simulation was performed. In this experiment the model was restarted from the same conditions as the control experiment at a $\mathrm{CO}_{2}$ concentration of $261 \mathrm{ppm}$ and was run for 200 years with a $\mathrm{CO}_{2}$ concentration of $522 \mathrm{ppm}$. The spatial patterns shown in this section are the differences between the climatologies computed from the second 100 years of the $\mathrm{CO}_{2}$ doubling run and the control run. Our results are compared to the responses of state-of-the-art climate models collected by CMIP3 (Meehl et al., 2007). 

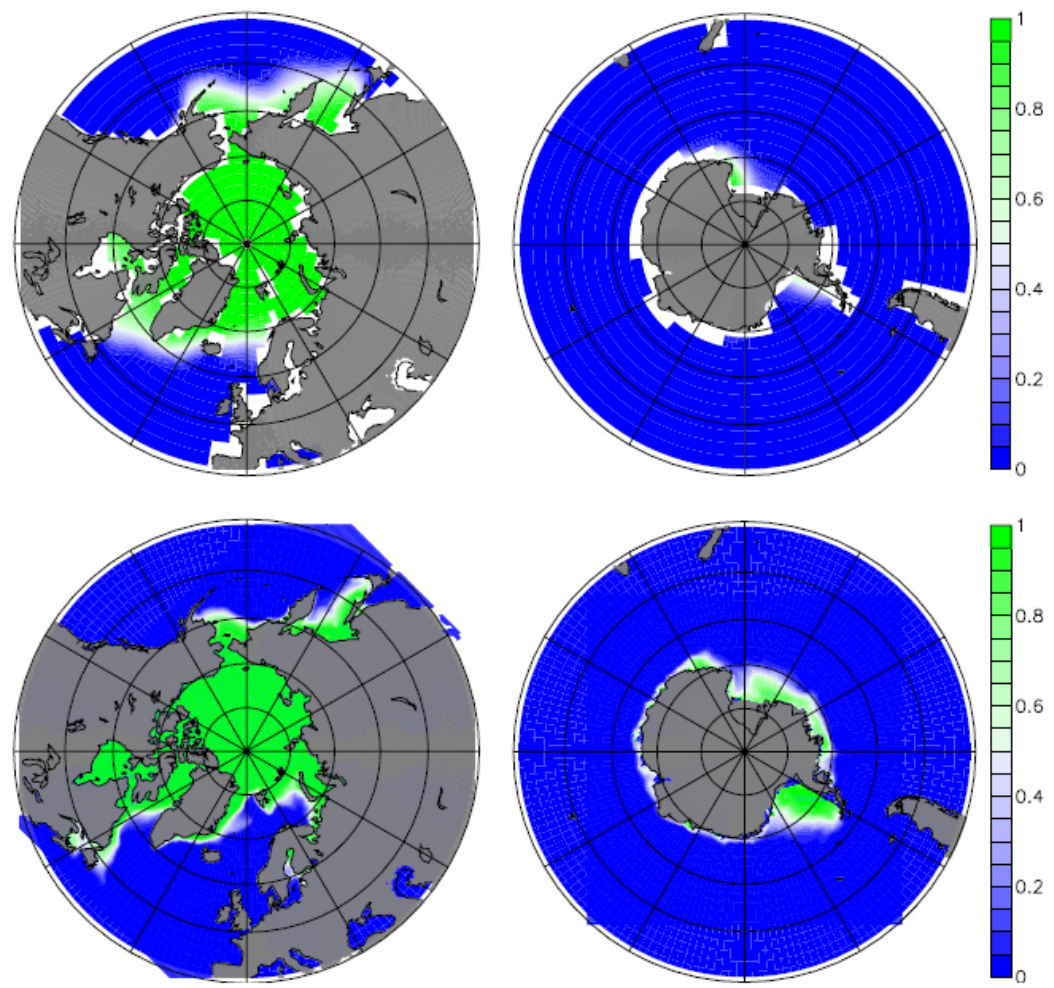

Fig. 12. The sea ice cover fraction in March in the Arctic (left) and the Antarctic (right). The top row shows the SPEEDO ensemble mean and bottom row the data from Cosimo (2008).
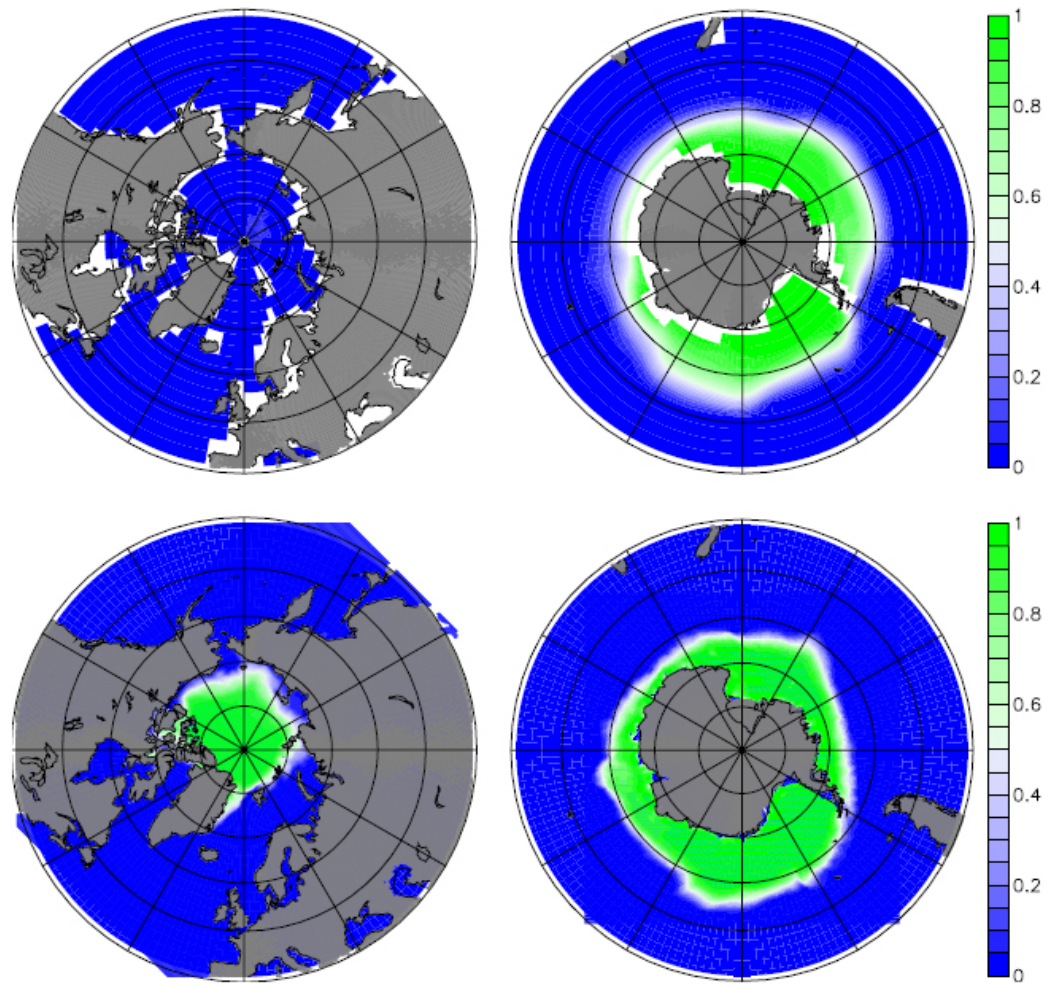

Fig. 12. Continued. The sea ice cover fraction in September in the Arctic (left) and the Antarctic (right). The top row shows the SPEEDO ensemble mean and bottom row the data from Cosimo (2008). 

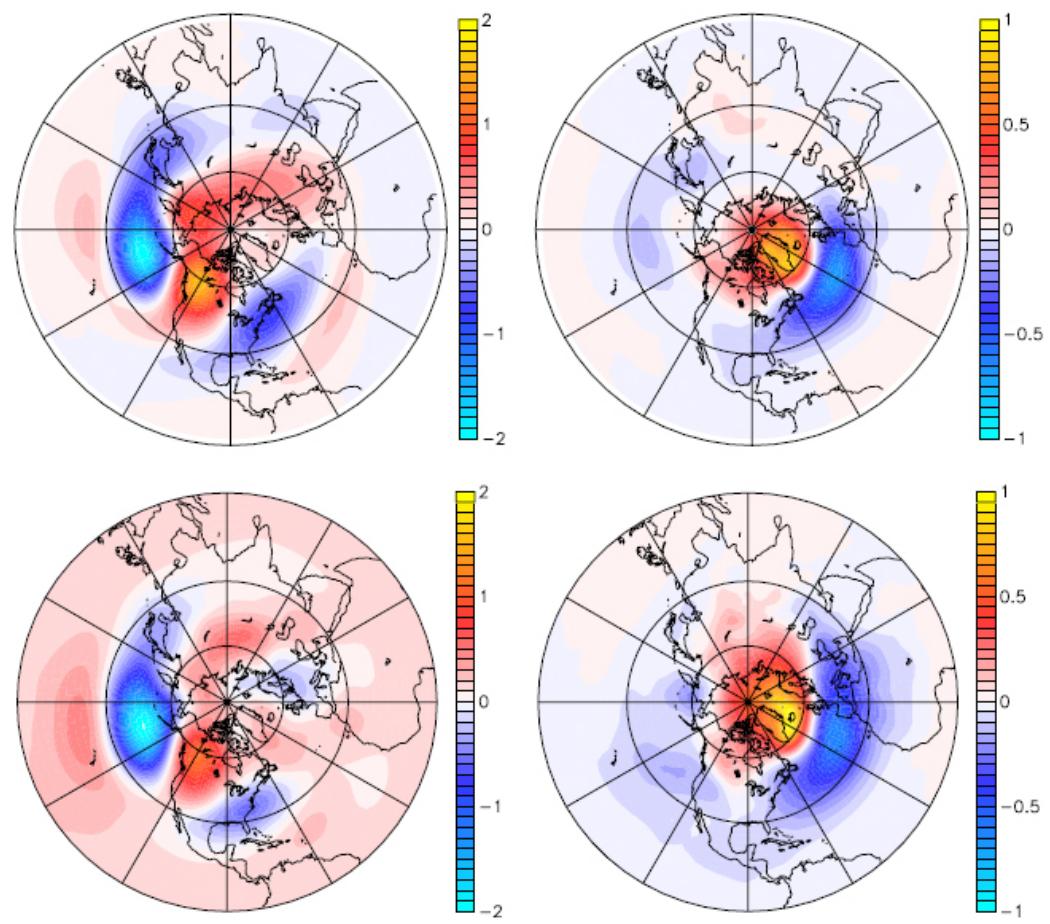

Fig. 13. The regression coefficient of the geopotential height anomalies at $500 \mathrm{hPa}$ with the PNA index (left) and the regression of the mean sea-level pressure anomalies with the NAO index (right). The top row shows the results for the SPEEDO model and the bottom row for the NCEP-NCAR Reanalysis (Kalnay et al., 1996).

The mean TOA radiation budget in the $\mathrm{CO}_{2}$ doubling experiment is $1.74 \mathrm{Wm}^{-2}$ larger than in the control run. The increase in the global mean surface temperature of $3.20 \mathrm{~K}$ in SPEEDO agrees well with the equilibrium climate sensitivity of 2.7-4.4 K in CMIP3 models. The climate sensitivity of SPEEDO is thus $1.84 \mathrm{KW}^{-1} \mathrm{~m}^{2}$.

The time series of the global mean $T_{2 \mathrm{~mm}}$ is shown in Fig. 20. The $T_{2 \mathrm{~m}}$ has a residual drift of approximately $1 \mathrm{~K}$ per century. The deep ocean still warms as well (not shown). The main characteristics of the spatial structure of the models $T_{2 \mathrm{~m}}$ response is similar to that of mean of the CMIP3 multi-model ensemble with the largest warming of $6-8 \mathrm{~K}$ in the Arctic due to the reduction of the snow cover and the sea ice extent. In addition, the $T_{2 \mathrm{~m}}$ increases more over land than over the ocean. The cooling in the Southern Ocean is due to the fact that the oscillations in the Antarctic sea ice volume described in Sect. 3.2.2 do not occur in the $\mathrm{CO}_{2}$ doubling experiment. The result is that the time mean sea ice volume is larger and the $T_{2 \mathrm{~m}}$ is lower in this experiment than in the control experiment.

The differences of the zonal averaged air temperature and specific humidity between the $2 \cdot \mathrm{CO}_{2}$ experiment and the control run are shown in Fig. 21. The response shows the well-known tropospheric warming and stratospheric cooling. The highest warming is found in the upper troposphere in the tropics and near the surface in the Arctic region. The increased greenhouse trapping causes the humidity to increase, with a maximum at the surface in the tropics, consistent with the Clausius Clapeyron relation. These features are consistent with results from the CMIP3 models.

The AMOC weakens significantly under $2 \cdot \mathrm{CO}_{2}$ conditions as can be seen in Fig. 22. The maximum overturning strength reduces by $8 \mathrm{~Sv}$ during the first 75 years and after that remains stable at a value of about $3 \mathrm{~Sv}$. The weakening is primarily associated with a reduction of North Atlantic Deep Water production.

The differences in the sea ice cover in March and September for both hemispheres are shown in Fig. 23. The sea ice cover in the Arctic is lower than in the control run which is to be expected. However the sea ice cover in the Southern Ocean in September increases. A comparison of the time series of the Antarctic sea ice volume in both runs shows that the control runs has two heat release events from between 1800 and 2000 while the $2 \cdot \mathrm{CO}_{2}$ run has none. As a result, the time mean sea ice cover in the control run is lower in the areas where the heat stored in the deep ocean is released (see Sect. 3.2.2).

\subsection{Application: transient climate response}

Earth system models of intermediate complexity, such as SPEEDO, can be used to explore a wide parameter range or to study long-term variability. Here we demonstrate an application of a long term climate projection and a large 

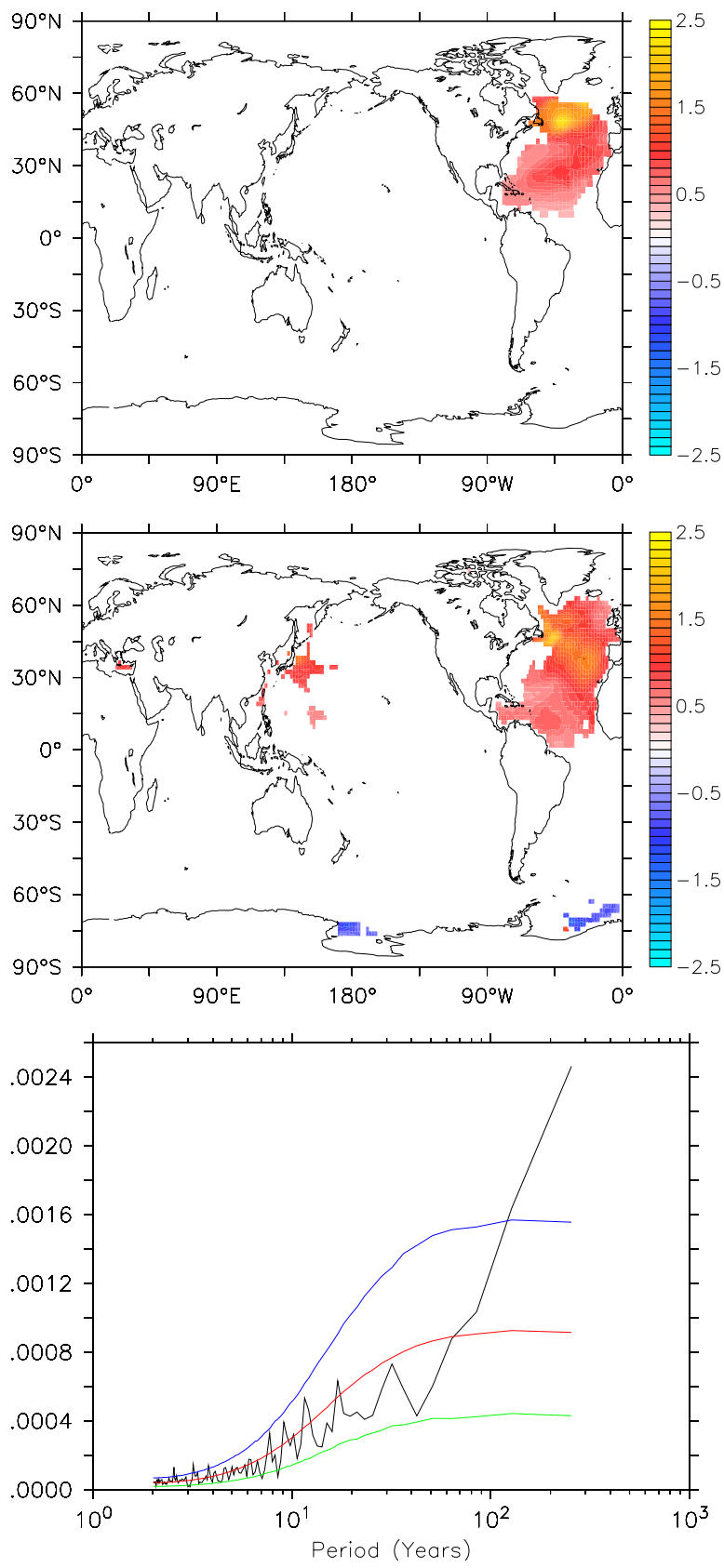

Fig. 14. The regression coefficient of the SST with the AMO index in $10^{-6} \mathrm{Ksm}^{-3}$ in SPEEDO (top) and the NCEP-NCAR reanalysis (Kalnay et al., 1996) for the period from 1960 to 2000 (center), and the power spectrum of the AMO index time series in $\mathrm{K}^{2}$ in SPEEDO (bottom). The simulated AR(1) spectrum (red), and the minimum (green) and maximum (blue) of the $95 \%$ confidence interval are also shown in the bottom panel.

perturbation in greenhouse gas concentrations. We performed a simulation of 1200 years with transient varying $\mathrm{CO}_{2}$ concentration (see Fig. 24). From 1800 to 2100 the same $\mathrm{CO}_{2}$ concentrations are used as in the ensemble experiment. From the year 2100 onward the $\mathrm{CO}_{2}$ concentration
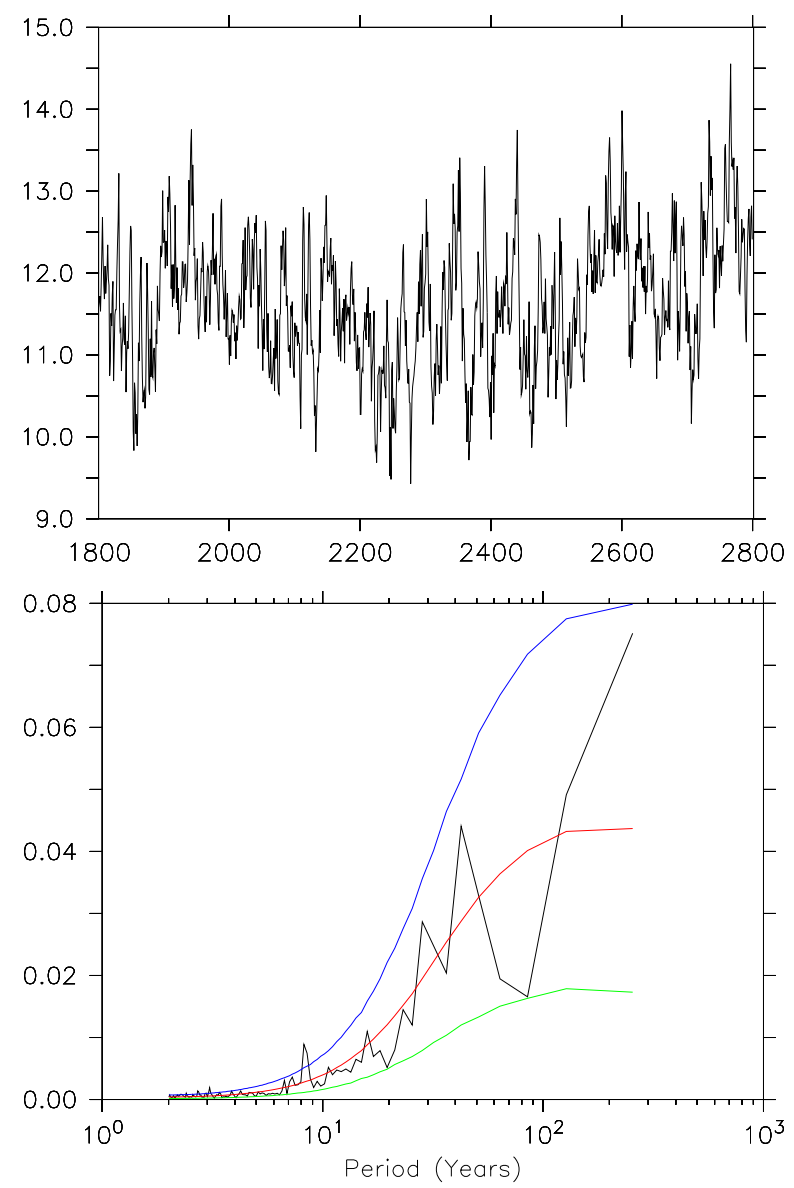

Fig. 15. The annual mean of the monthly maximum strength of the AMOC in the North Atlantic in Sv in the control run (top) and the power spectrum of this time series in $\mathrm{Sv}^{2}$ (bottom). The simulated AR(1) spectrum (red), and the minimum (green) and maximum (blue) of the $95 \%$ confidence interval are also shown in the bottom panel.

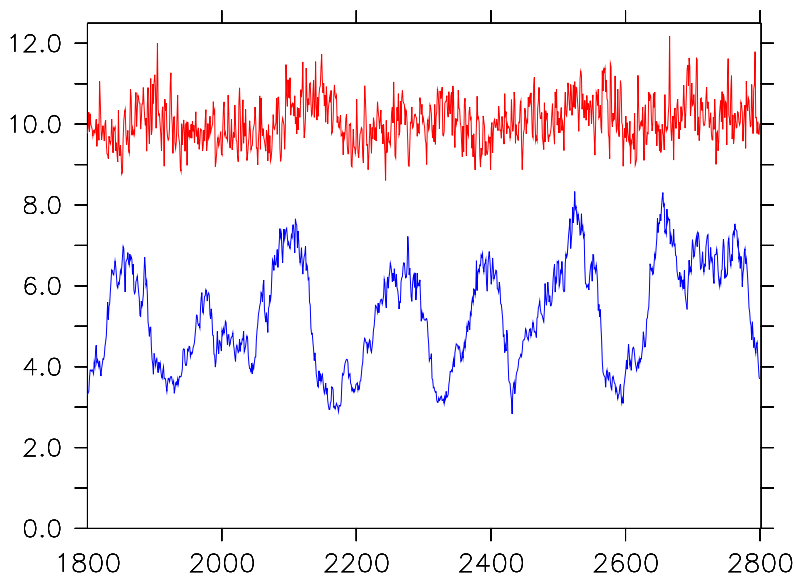

Fig. 16. The annual mean Arctic (red) and Antarctic (blue) sea ice volume in $10^{12} \mathrm{~m}^{3}$ during the 1000 -year control run. 

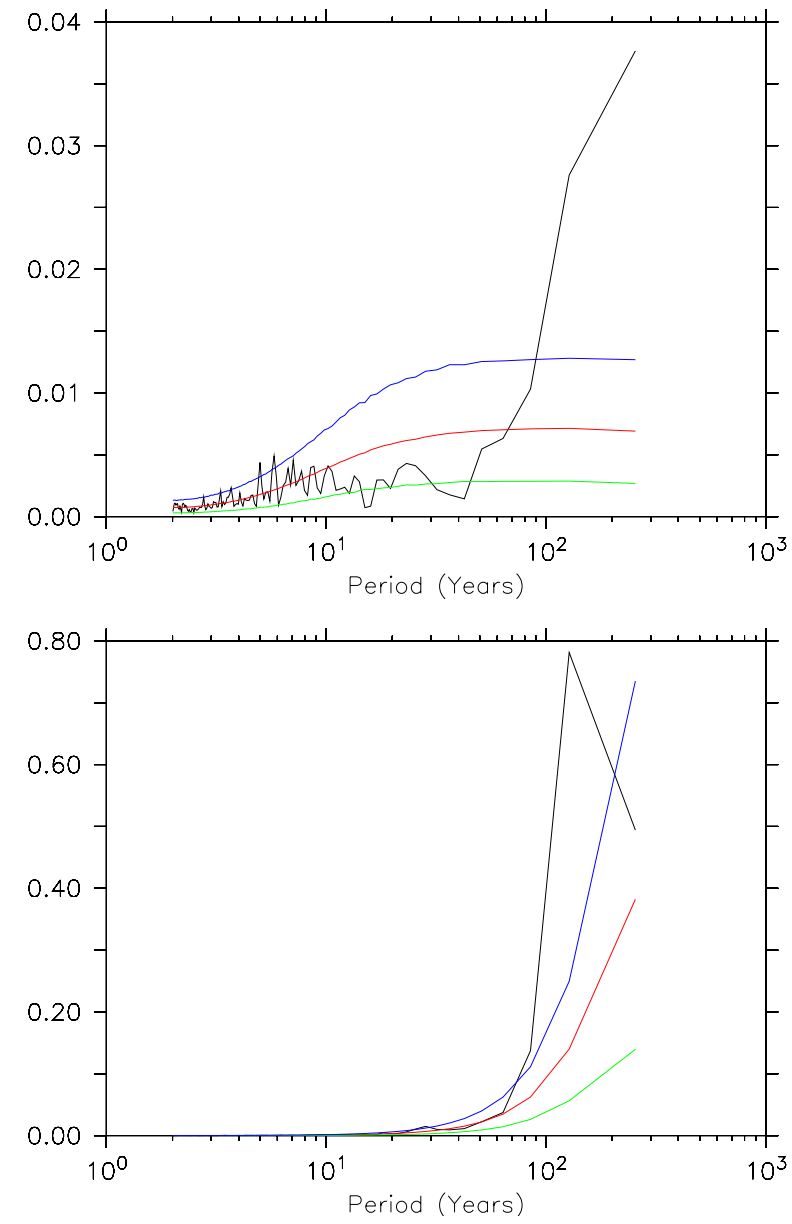

Fig. 17. The power spectra of the Arctic (top) and Antarctic (bottom) sea ice volume in $10^{24} \mathrm{~m}^{6}$ in the control run. The simulated $\mathrm{AR}(1)$ spectrum (red), and the minimum (green) and maximum (blue) of the $95 \%$ confidence interval are also shown.

increases at a decreasing rate until a maximum concentration of $1967 \mathrm{ppm}$ is reached in the year 2282. Hereafter, the $\mathrm{CO}_{2}$ concentration decreases slowly due to uptake in the ocean and sedimentation of calcium carbonate. After the year 2000 an extra freshwater flux, $F_{\mathrm{G}}$, was added to the runoff of Greenland to account for the melting of its land ice sheet. The melting rate of the ice sheet is prescribed as

$F_{\mathrm{G}}=a \cdot \max \left(<T_{2 \mathrm{~m}}>-<T_{2 \mathrm{~m}, 2000}>, 0\right)$

where $<T_{2 \mathrm{~m}}>$ is the ten year running mean of the annual global mean two meter air temperature, $\left\langle T_{2 \mathrm{~m}, 2000}>\right.$ is the value of this quantity in the year 2000, and the fresh water flux coefficient $a=10^{4} \mathrm{~m}^{3} \mathrm{~s}^{-1} \mathrm{~K}^{-1}$ (Marsh et al., 2007).

The time series of the annual global mean $T_{2 \mathrm{~m}}$ is shown in Fig. 24. The model shows a large warming. At very high $\mathrm{CO}_{2}$ concentrations, the model response is too strong. The $T_{2 \mathrm{~m}}$ increases by $16 \mathrm{~K}$ while one would expect an increase of $8-9 \mathrm{~K}$ based on the climate sensitivity determined in the 2. $\mathrm{CO}_{2}$ experiment.

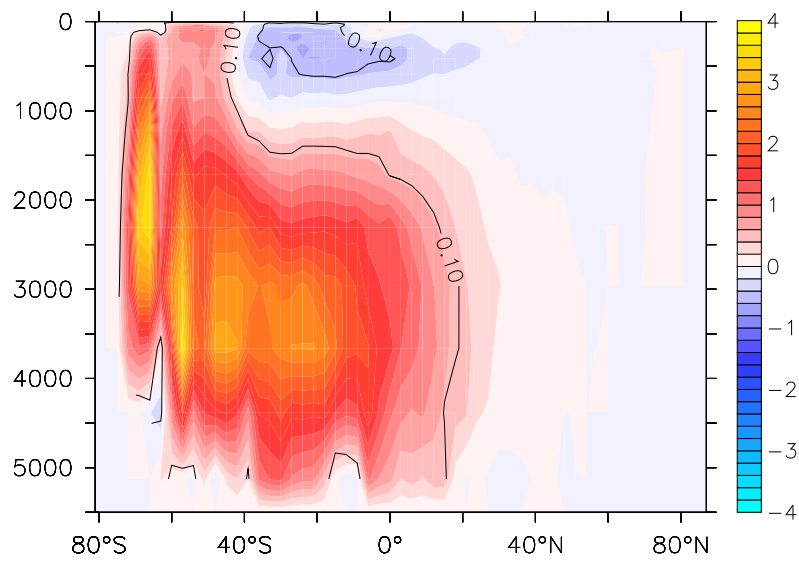

Fig. 18. The regression coefficient of the Antarctic sea ice volume with the strength of the global meridional overturning circulation. The regression coefficient is given in $10^{-12} \mathrm{Svm}^{-3}$. The contour indicates the area where the regression coefficient is statistically significant.

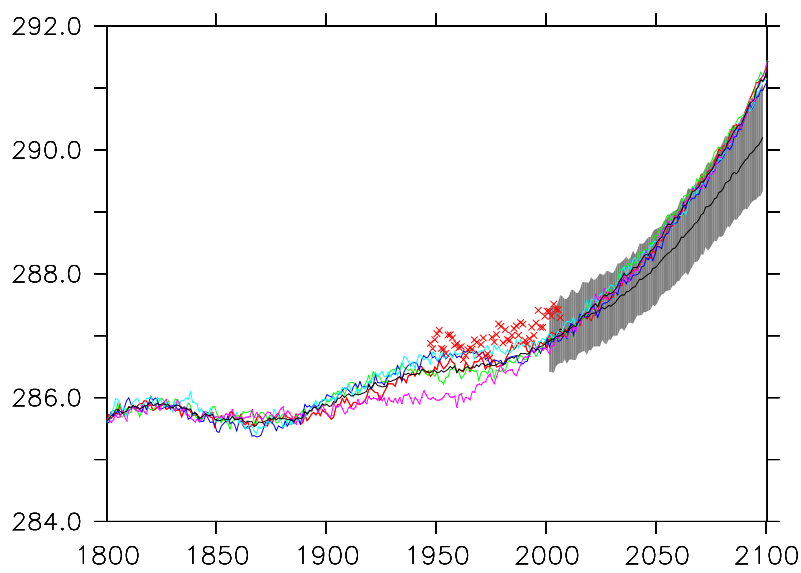

Fig. 19. The annual global mean two meter temperature in $\mathrm{K}$ from 1800 to 2100 in each of the SPEEDO ensemble members (thin red, green, light blue, blue and purple lines) and the ensemble mean (thick black line). Also shown are the reanalysis data from 1950 to 2008 (red crosses) and the multi-model ensemble mean two meter temperature of all SRES A2 CMIP3 simulations (thin black line). The one standard deviation spread in the CMIP3 ensemble is shown in gray.

The time series of the annual global mean TOA and surface energy budgets in Fig. 25 show that the ocean/sea-ice model takes up heat during most of the period. The maximum heat uptake occurs in the first half of the 22nd century. This is roughly 150 years earlier than the maximum in the $\mathrm{CO}_{2}$ concentration. At the end of the run, the TOA budget has returned to its initial value. However, the final value of the surface budget is about $0.5 \mathrm{Wm}^{-2}$ smaller than its starting value. This is in agreement with the slight increase of the global mean $T_{2 \mathrm{~m}}$ which indicates that the ocean is still taking up heat. 

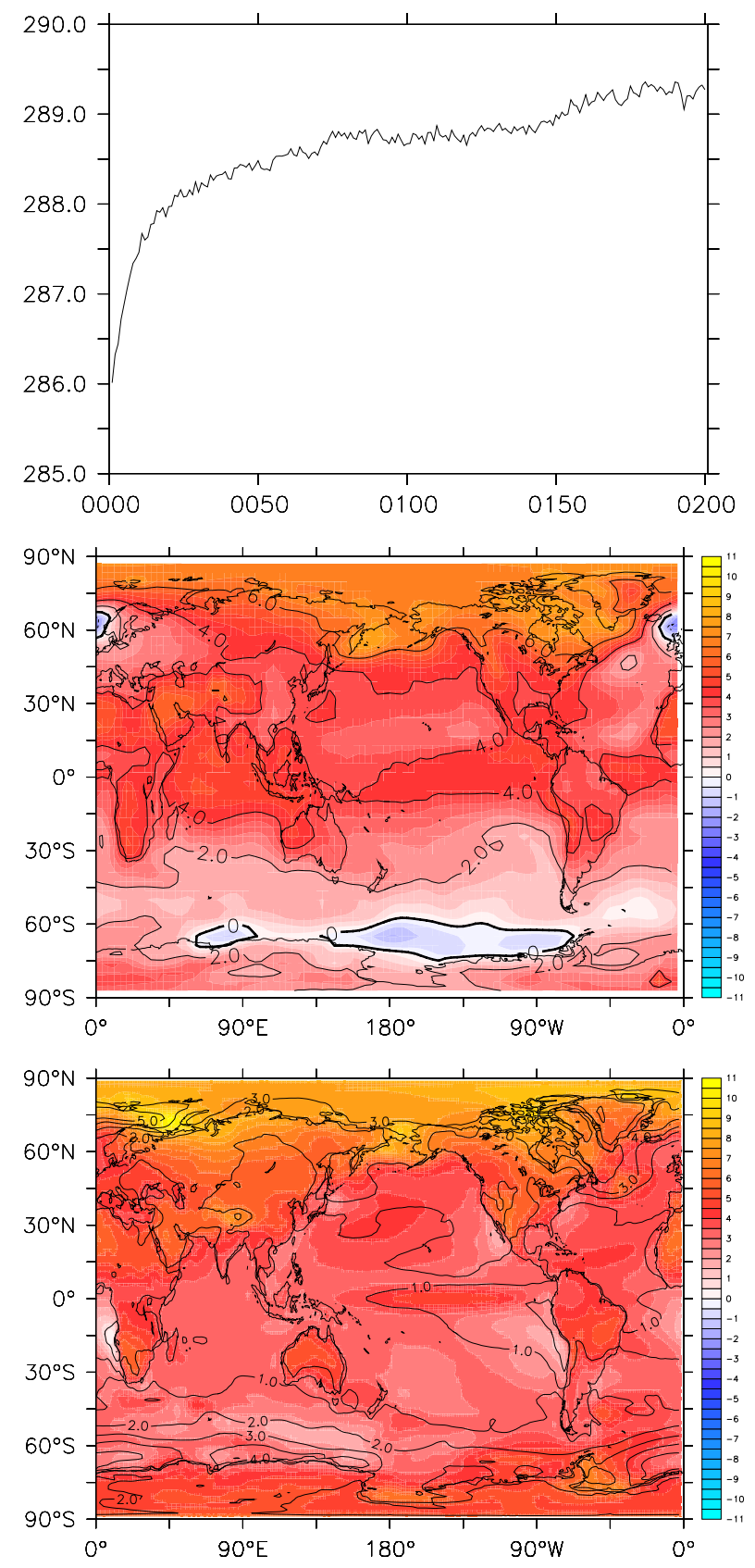

Fig. 20. The time series of the annual mean two meter temperature in SPEEDO (top), the difference in the 100-year mean two meter temperature of the $2 \cdot \mathrm{CO}_{2}$ experiment and the control run in the second 100 years in SPEEDO (centre), and the mean change in the two meter air temperature to a doubling of the $\mathrm{CO}_{2}$ concentration in the CMIP3 multi-model ensemble (bottom). The contours in the lower panel indicate the standard deviation of the CMIP3 ensemble. All quantities are in $\mathrm{K}$.

This experiment shows that the model can be used to make long simulations and explore wide parameter ranges. It also shows that there are limits to the use of the model. This is the main reason why we present this experiment. The model
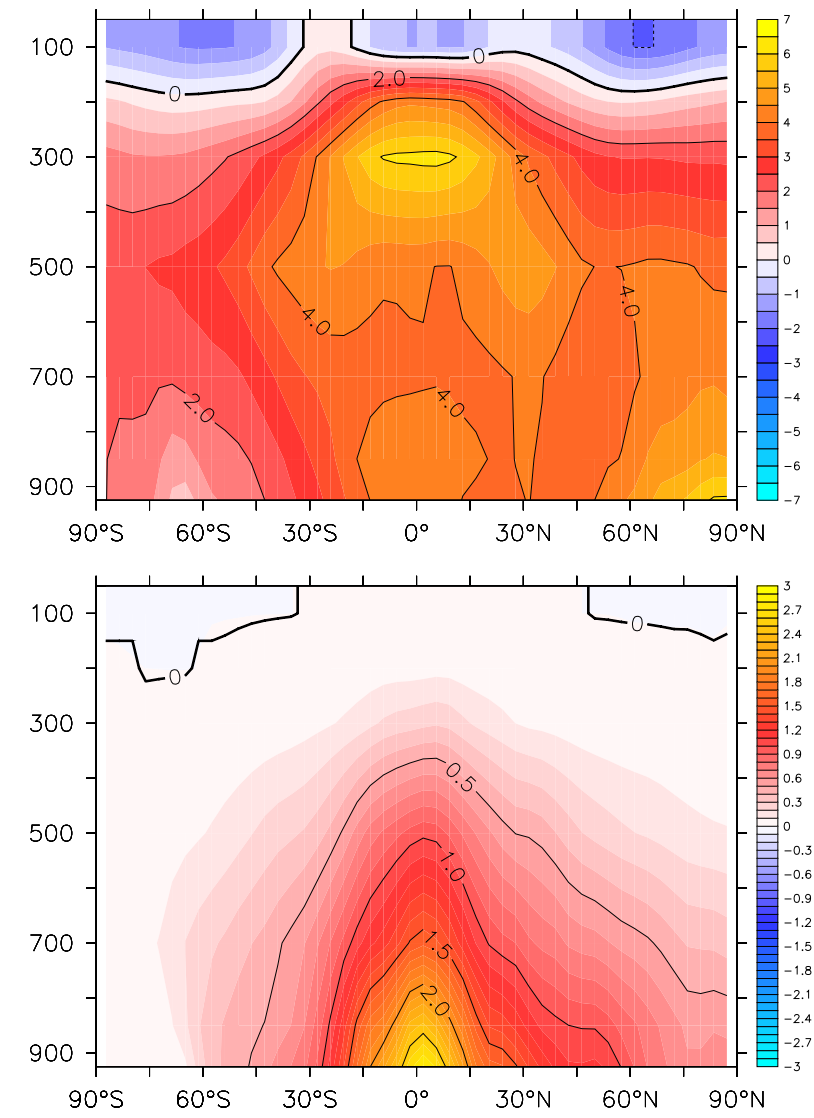

Fig. 21. The difference of the zonal mean air temperature in $\mathrm{K}$ (top) and zonal mean specific humidity in $10^{-3} \mathrm{kgkg}^{-1}$ (bottom) of the $2 \cdot \mathrm{CO}_{2}$ experiment and the control run.

heats up much more at high $\mathrm{CO}_{2}$ concentrations than is expected from it's climate sensitivity computed from the $2 \cdot \mathrm{CO}_{2}$ experiment. There are a number of limitations associated with the parameterisations used in the model because they are simplified to make the model fast. One of the problems is that only the absorptivity parameter in the $\mathrm{CO}_{2}$ band changes with the $\mathrm{CO}_{2}$ concentration. For this experiment with high $\mathrm{CO}_{2}$ levels, the bandwidth probably needs to be changed as well. Also, there is large dependence on the relative humidity profile in a number of parameterisations, which go beyond the range of application. It shows that when wide parameter ranges are explored, the models physics should always be checked for physical realism.

\section{Conclusions}

The coupled model of intermediate complexity SPEEDO was presented in this paper. This model is fast due to its simplified physics parameterisations and relatively coarse resolution. However, the model is a full 3-D model of 

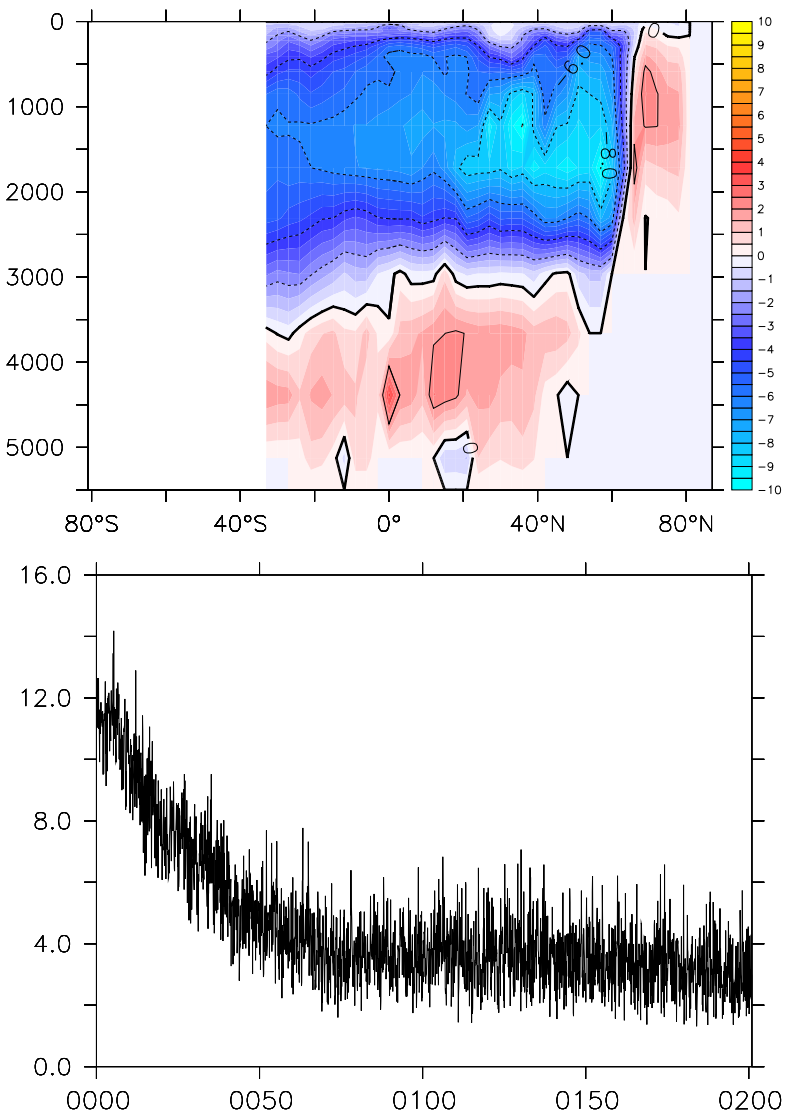

Fig. 22. The difference of the Atlantic meridional overturning stream function between the $2 \cdot \mathrm{CO}_{2}$ experiment and the control run (top) and the time series of the maximum AMOC strength in the 2. $\mathrm{CO}_{2}$ experiment (bottom), both in $\mathrm{Sv}$.

the atmosphere and the ocean, using primitive equations and a realistic configuration of continents, orography and bathymetry. Important new features with respect to its predecessor ECBILT-CLIO are the use of primitive equations, the lack of flux correction and fully interactive clouds and radiation. Only land surface albedo (monthly climatology), maximum soil moisture capacity (fixed), solar forcing and atmospheric composition are prescribed. Earlier coupled SPEEDO versions contained only basin-scale ocean models and have been extensively used in climate variability studies (e.g., Molteni, 2003; Hazeleger and Haarsma, 2005; Hazeleger et al., 2005; Bracco et al., 2005; Kucharski et al., 2006; Breugem et al., 2007). Here, we reported on a globally coupled SPEEDO model, without flux corrections.

The validation of the model shows that it performs well in a recent climate setting. The mean state of the atmosphere, especially the stationary waves in the mid-latitudes are well simulated given the coarse resolution. Also, the mid-latitude inter-annual variability and the long-term trends forced by rising greenhouse gas concentrations compare well to observations and to CMIP3 models. The climate sensitivity
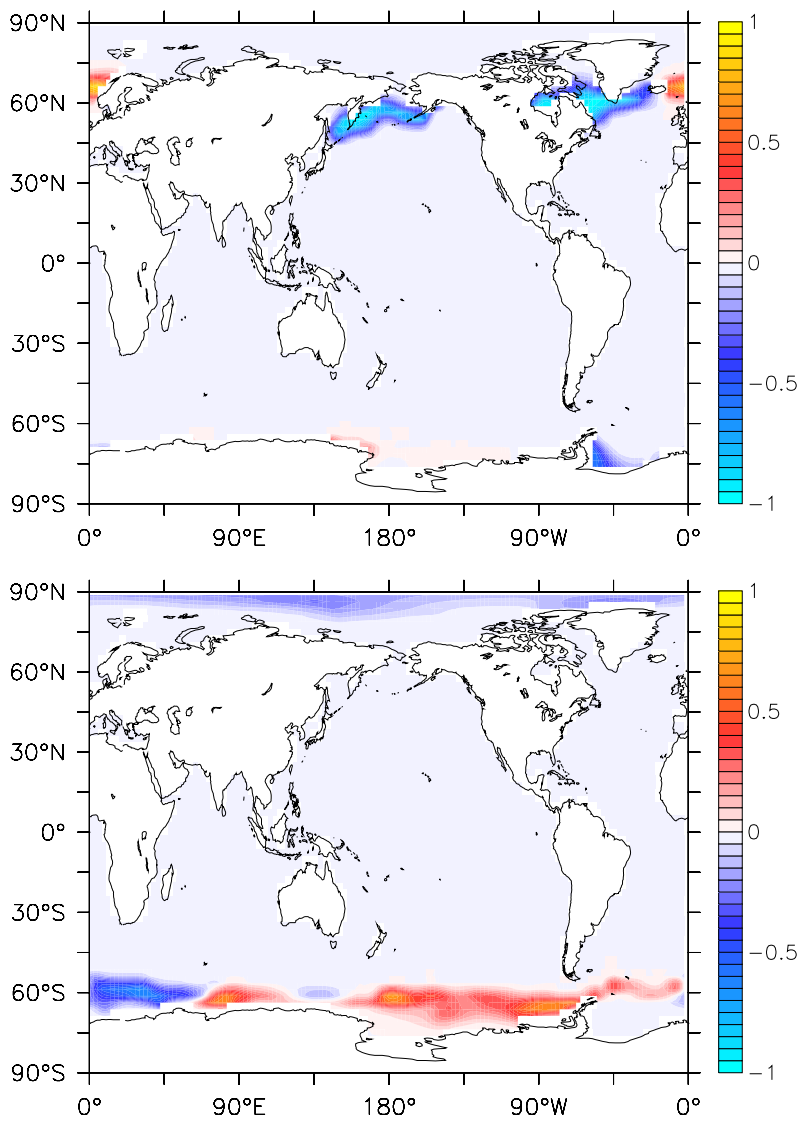

Fig. 23. The change in the sea ice cover in March (top) and September (bottom) of the $2 \cdot \mathrm{CO}_{2}$ experiment and the control run.

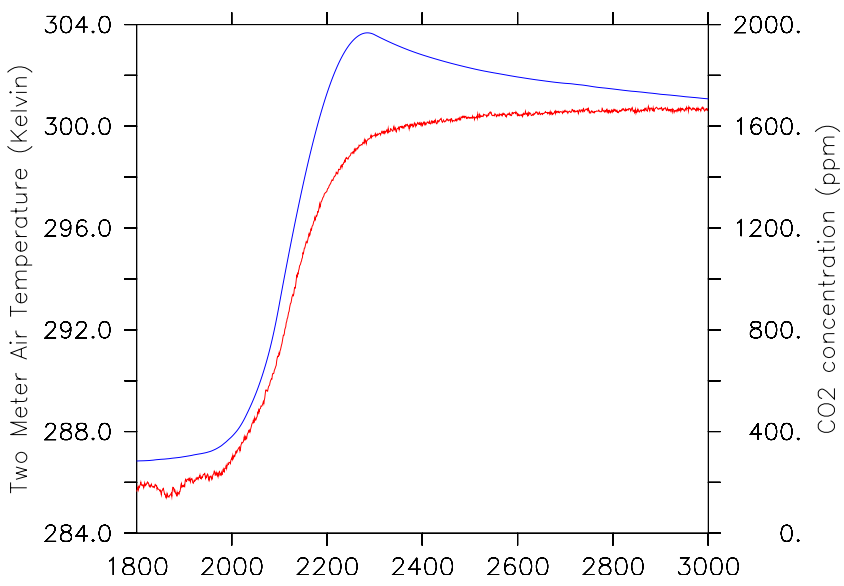

Fig. 24. The annual global mean two meter air temperature in $\mathrm{K}$ (red) and prescribed $\mathrm{CO}_{2}$ concentration in ppm (blue) in the scenario run.

is within the range of state-of-the-art models and the main features of spatial variability, such as Arctic amplification, reducing AMOC, and tropospheric heating, are well simulated. 


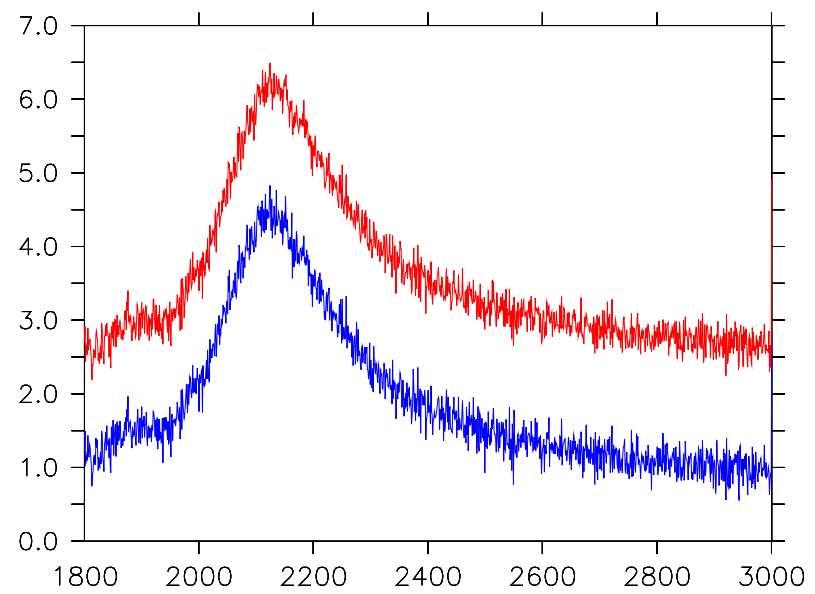

Fig. 25. The annual global mean TOA net radiation budget (red) and surface heat budget (blue) in $\mathrm{Wm}^{-2}$ in the scenario run.

The main biases are a too large seasonal cycle in the sea ice cover, a double intertropical convergence zone and a cold mid-latitude surface ocean. In addition, the meridional overturning circulation in the Atlantic is rather weak and the centennial variability in the sea ice volume may not be realistic. However, these biases are within the range of the inter-model variations of state-of-the-art models of CMIP3.

So, despite the coarse resolution realistic climate features are simulated. Apparently, the major climate feedbacks are included in the model. This makes the model very suitable to study past, recent and projected future climates. In particular large ensembles or long runs can be easily done on a single workstation. There are caveats, however. We deliberately showed that the models sensitivity may be too high at high levels of greenhouse gases. Also, this model does not include a dynamical ice-sheet model and other components of the Earth system such as dynamic vegetation or atmospheric chemistry. These limitations should be borne in mind when using the model far out of the range of recent climate fluctuations. In addition, the coarse resolution inhibits the use of the model for very regionalised climate studies. Limitations of intermediate complexity models are inherent to the chosen strategy. We believe that this model can be very useful in the hierarchy of simple 1-D models to highly complex 3-D earth system models.

The source code of the SPEEDO model is available at the URL http://www.knmi.nl/onderzk/CKO/SPEEDO.html.

Acknowledgements. We acknowledge the modelling groups, the Program for Climate Model Diagnosis and Intercomparison (PCMDI) and the WCRP's Working Group on Coupled Modeling (WGCM) for their roles in making available the WCRP CMIP3 multi-model dataset. Support of this dataset is provided by the Office of Science, US Department of Energy.

Edited by: D. Lunt

\section{References}

Bracco, A., Kucharski, F., Molteni, F., Hazeleger, W., and Severijns, C.: Internal and forced modes of variability in the Indian Ocean, Geophys. Res. Lett., 32, L12707, doi:10.1029/2005GL023154, 2005.

Breugem, W. P., Hazeleger, W., and Haarsma, R. J.: Mechanisms of northern tropical Atlantic variability and response to $\mathrm{CO}_{2}$ doubling, J. Climate, 20, 11, 2691-2705, 2007.

Brovkin, V., Bendtsen, J., Claussen, M., Ganopolski, A., Kubatzki, C., Petoukhov, V., Andreev, A.: Carbon cycle, vegetation and climate dynamics in the Holocene: Experiments with the CLIMBER-2 model, Global Biogeochem. Cy., 16, 1139-1151, doi: 10.1029/2001GB001662, 2002.

Claussen, M., Mysak, L. A., Weaver, A. J., et al.: Earth system models of intermediate complexity: closing the gap in the spectrum of climate system models, Clim. Dynam., 18, 579-586, 2002.

Cosimo, J.: Bootstrap sea ice concentrations from NIMBUS-7 SMMR and SSM/I, January 1978 to December 2007, Boulder, Colorado USA: National Snow and Ice Data Center, digital media, 1999, updated 2008.

Cunningham, S. A., Kanzow, T., Rayner, D., Baringer, M. O., Johns, W. E., Marotzke, J., Longworth, H. R., Grant, E. M., Hirschi, J. J.-M., Beal, L. M., Meinen, C. S., and Bryden, H. L.: Temporal variability of the Atlantic Meridional Overturning Circulation at 26N, Science, 317, 935-938, 2007.

Dai, A., Wigley, T. M. L., Boville, B. A., Kiehl, J. T., and Buja, L. E.: Climates of the Twentieth and Twenty-first Centuries Simulated by the NCAR Climate System Model, J. Climate, 14, 485519, 2001.

Danabasoglu, G. and McWilliams, J. C.: Sensitivity of the global ocean circulation to parameterizations of mesoscale tracer transports, J. Climate, 8, 2967-2987, 1995.

Farneti, R. and Vallis, G. K.: An Intermediate Complexity Climate Model (ICCMp1) based on the GFDL flexible modelling system, Geosci. Model Dev., 2, 73-88, 2009.

Gent, P. R. and Williams, J. C.: Isopycnal mixing in ocean circulation models, J. Phys. Oceanogr., 20, 150-155, 1990.

Goose, H. and Fichefet, T.: Importance of ice-ocean interactions for the global ocean circulation: a model study, J. Geophys. Res., 104(C10), 23337-23355, 1999.

Hazeleger, W., Severijns, C., Seager, R., and Molteni, F.: Tropical Pacific-driven decadal energy transport variability, J. Climate, 18, 2037-2051, 2005.

Hazeleger, W. and Haarsma, R. J.: Sensitivity of tropical Atlantic climate to mixing in a coupled ocean-atmosphere model, Clim. Dynam., 25, 4, 387-99, 2005.

Hazeleger, W., Severijns, C., Haarsma, R., Selten, F., and Sterl, A.: SPEEDO: model description and validation of a flexible coupled model for climate studies, Technical report 257, KNMI, De Bilt, The Netherlands, 38 pp., 2003.

Hurrell, J. W.: Decadal trends in the North Atlantic Oscillation and relationships to regional temperature and precipitation, Science, 269, 676-679, 1995.

Johns, T. C., Durman, C. F., Banks, H. T., Roberts, M. J., McLaren, A. J., Ridley, J. K., Senior, C. A., Williams, K. D., Jones, A., Rickard, G. J., Cusack, S., Ingram, W. J., Crucifix, M., Sexton, D. M. H., Joshi, M. M., Dong, B.-W., Spencer, H., Hill, R. S. R., Gregory, J. M., Keen, A. B., Pardaens, A. K., Lowe, J. A., Bodas-Salcedo, A., Stark, S., and Searl, Y.: The New 
Hadley Centre Climate Model (HadGEM1): Evaluation of Coupled Simulations, J. Climate, 19, 1327-1352, 2006.

Joos, F., Prentice, I. C., Sitch, S., Meyer, R., Hooss, G., Plattner, G.-K., Gerber, S., and Hasselmann, K.: Global warming feedbacks on terrestrial carbon uptake under the Intergovernmental Panel on Climate Change (IPCC) emission scenarios, Global Biogeochem. Cy., 15, 891-907, 2001.

Kalnay, E., Kanamitsu, M., Kistleret, R., et al.: The NCEP/NCAR 40-year reanalysis project, B. Am. Meteorol. Soc., 77, 437-470, 1996.

Kiehl, J. T. and Trenberth, K. E.: Earths annual global mean energy budget, B. Am. Meteorol. Soc., 78 pp., 1997.

Knight, J. R., Allan, R. J., Folland, C. K., et al.: A signature of persistent natural thermohaline circulation cycles in observed climate, Geophys. Res. Lett., 32, L20708, doi:10.1029/2005GL024233, 2005.

Kucharski, F., Molteni, F., and Bracco, A.: Decadal interactions between the western tropical Pacific and the North Atlantic Oscillation, Clim. Dynam., 26, 79-91, 2006.

Marotzke, J.: Influence of convective adjustment on the stability of the thermohaline circulation, J. Phys. Oceanogr., 21, 903-907, 1991.

Marsh, R., Hazeleger, W., Yool, A., and Rohling, E.: Stability of the thermohaline circulation under millennial $\mathrm{CO}_{2}$ forcing and two alternative controls on Atlantic salinity, Geophys. Res. Lett., 34, L03605, doi:10.1029/2006GL027815, 2007.

McPhaden, M. J., Busalacchi, A. J., Cheney, R., Donguy, J.-R., Gage, K. S., Halpern, D., Ji, M., Julian, P., Meyers, G., Mitchum, G. T., Niiler, P. P., Picaut, J., Reynolds, R. W., Smith, N., and Takeuchi, K.: The Tropical Ocean-Global Atmosphere observing system: A decade of progress, J. Geophys. Res., 103(14), 14169-14240, 1998.

Meehl, G. A., Covey, C., Delworth, T., Latif, M., McAvaney, B., Mitchell, J. F. B., Stouffer, R. J. and Taylor, K. E.: The WCRP CMIP3 multi-model dataset: A new era in climate change research, B. Am. Meteorol. Soc., 88, 1383-1394, 2007.

Mellor, G. L. and Yamada, T.: Development of a turbulence closure model for geophysical fluid problems, Rev. Geophys. Space Phys., 16, 1829-1846, 1982.

Molteni, F.: Atmospheric simulations using a GCM with simplified physical parameterizations. I: Model climatology and variability in multi-decadal experiments, Clim. Dynam., 20, 175-191, 2003.

Montenegro, A., Brovkin, V., Eby, M., Archer, D., and Weaver, A. J.: Long term fate of anthropogenic carbon, Geophys. Res. Lett., 34, L19707, doi:10.1029/2007GL030905, 2007.

Nakicenovic, N., Alcamo, J., Davis, G., et al.: Special Report on Emissions Scenarios: A Special Report of Working Group III of the Intergovernmental Panel on Climate Change, Cambridge University Press, Cambridge, UK, 599 pp., 2000.

Opsteegh, J. D., Haarsma, R. J., Selten, F. M., and Kattenberg, A.: ECBILT: A dynamic alternative to mixed boundary conditions in ocean models, Tellus A, 50, 348-367, 1998.

Orsi, A. H., Johnson, G. C., and Bullister, J. L.: Circulation, mixing and production of Antarctic bottom water, Prog. Oceanogr., 43, 55-109, 1999.

Reynolds, R. W., Rayner, N. A., Smith, T. M., Stokes, D. C., and Wang, W.: An Improved In Situ and Satellite SST Analysis for Climate, J. Climate, 15, 1609-1625, 2002.
Roche, D. M., Dokken, T. M., Goosse, H., Renssen, H., and Weber, S. L.: Climate of the Last Glacial Maximum: sensitivity studies and model-data comparison with the LOVECLIM coupled model, Clim. Past, 3, 205-224, 2007, http://www.clim-past.net/3/205/2007/.

Rossow, W. B. and Schiffer, R. A.: ISCCP Cloud Data Products, B. Am. Meteorol. Soc., 71, 2-20, 1991.

Schmidt, G. A., Ruedy, R., Hansen, J. E., Aleinov, I., Bell, N., Bauer, M., Bauer, S., Cairns, B., Canuto, V., Cheng, Y., Del Genio, A., Faluvegi, G., Friend, A. D., Hall, T. M., Hu, Y,. Kelley, M., Kiang, N. Y., Koch, D., Lacis, A. A., Lerner, J., Lo, K. K., Miller, R. L., Nazarenko, L., Oinas, V., Perlwitz, J., Perlwitz, J., Rind, D., Romanou, A., Russell, G. L., Sato, M., Shindell, D. T., Stone, P. H., Sun, S., Tausnev, N.,Thresher, D., and Yao, M.S.: Present-Day Atmospheric Simulations Using GISS ModelE: Comparison to In Situ, Satellite, and Reanalysis Data, J. Climate, 19, 153-192, 2006.

Severijns, C. A. and Hazeleger, W.: Optimizing parameters in an atmospheric general circulation model, J. Climate, 18(17), 35273535, 2005.

Smith, R. S., Gregory, J. M., and Osprey, A.: A description of the FAMOUS (version XDBUA) climate model and control run, Geosci. Model Dev., 1, 53-68, 2008.

Stephens, C., Antonov, J. I., Boyer, T. P., Conkright, M. E., Locarnini, R. A., O'Brien, T. D., and Garcia, H. E.: World Ocean Atlas 2001, Volume 1: Temperature, in: NOAA Atlas NESDIS 49, edited by: Levitus, S., US Government Printing Office, Wash., DC, 167 pp., 2002.

Sutton, R. T. and Hodson, D. L. R.: Atlantic Ocean Forcing of North American and European Summer Climate, Science, 309, 115118, doi:10.1126/science.1109496, 2005.

Tiedke, M.: A comprehensive mass flux scheme for cumulus parameterization in large-scale models, Mon. Weather Rev., 117, 1779-1800, 1993.

Trenberth, K. E. and Caron, J. M.: Estimates of meridional atmosphere and ocean heat transports, J. Climate, 14, 3433-3443, 2001.

Trenberth, K. E., Fasullo, J. T., and Kiehl, J. T.: Earth's Global Energy Budget, B. Am. Meteorol. Soc., 90, 311-324, 2009.

van Oldenborgh, G. J., Philip, S. Y., and Collins, M: El Niño in a changing climate: a multi-model study, Ocean Sci., 1, 81-95, 2005 ,

http://www.ocean-sci.net/1/81/2005/.

Wallace, J. M. and Gutzler, D. S.: Teleconnections in the geopotential height field during the Northern Hemisphere Winter, Mon. Weather Rev., 109, 784-812, 1981

Weaver, A. J., Eby, M., Wiebe, E. C., Bitz, C. M., Duffy, P. B., Ewen, T. L., Fanning, A. F., Holland, M. M., MacFadyen, A., Matthews, H. D., Meissner, K. J., Saenko, O., Schmittner, A., Wang, H., and Yoshimori, M.: The UVic Earth System Climate Model: Model description, climatology and application to past, present and future climates, Atmos. Ocean, 39, 361-428, 2001.

Xie, P. and Arkin, P. A.: Analysis of global monthly precipitation using gauge observations, satellite estimates, and numerical model predictions, J. Climate, 9, 840-858, 1996. 